\title{
Genetic and Pharmacologic Manipulation of TLR4 Has Minimal Impact on Ethanol Consumption in Rodents
}

\author{
๑R. Adron Harris, ${ }^{1}{ }^{\circledR}$ Michal Bajo, ${ }^{2}$ Richard L. Bell, ${ }^{3}$ Yuri A. Blednov, ${ }^{1}$ Florence P. Varodayan, ${ }^{2}$ Jay M. Truitt, ${ }^{1}$ \\ (1) Giordano de Guglielmo, ${ }^{2}$ Amy W. Lasek, ${ }^{4}$ Marian L. Logrip, ${ }^{2}$ 'Leandro F. Vendruscolo, ${ }^{2}$ Amanda J. Roberts, ${ }^{5}$ \\ Edward Roberts, ${ }^{6}{ }^{\circledR}$ Olivier George, ${ }^{2}$ Jody Mayfield, ${ }^{1}$ Timothy R. Billiar, ${ }^{7}$ David J. Hackam, ${ }^{7}{ }^{\circ}$ R. Dayne Mayfield, ${ }^{1}$ \\ George F. Koob, ${ }^{2}$ Marisa Roberto, ${ }^{2}$ and ${ }^{\mathbb{G}}$ Gregg E. Homanics ${ }^{8}$ \\ ${ }^{1}$ Waggoner Center for Alcohol and Addiction Research, The University of Texas at Austin, Austin, Texas 78712, ${ }^{2}$ Committee on the Neurobiology of \\ Addictive Disorders, The Scripps Research Institute, La Jolla, California 92037, ${ }^{3}$ Department of Psychiatry, Institute of Psychiatric Research, Indiana \\ University School of Medicine, Indianapolis, Indiana 46202, ${ }^{4}$ Department of Psychiatry, University of Illinois, Chicago, Illinois 60612, ${ }^{5}$ Molecular and \\ Cellular Neuroscience Department and Mouse Behavioral Assessment Core, The Scripps Research Institute, La Jolla, California 92037, ${ }^{6}$ Deparment of \\ Chemistry, The Scripps Research Institute, La Jolla, California 92037, ${ }^{7}$ Department of Surgery, University of Pittsburgh, Pittsburgh, Pennsylvania 15213, \\ and ${ }^{8}$ Departments of Anesthesiology and Pharmacology and Chemical Biology, University of Pittsburgh, Pittsburgh, Pennsylvania 15261
}

Toll-like receptor 4 (TLR4) is a critical component of innate immune signaling and has been implicated in alcohol responses in preclinical and clinical models. Members of the Integrative Neuroscience Initiative on Alcoholism (INIA-Neuroimmune) consortium tested the hypothesis that TLR4 mediates excessive ethanol drinking using the following models: (1) Tlr4 knock-out (KO) rats, (2) selective knockdown of Tlr4 mRNA in mouse nucleus accumbens (NAc), and (3) injection of the TLR4 antagonist (+)-naloxone in mice. Lipopolysaccharide (LPS) decreased food/water intake and body weight in ethanol-naive and ethanol-trained wild-type (WT), but not Tlr4 KO rats. There were no consistent genotypic differences in two-bottle choice chronic ethanol intake or operant self-administration in rats before or after dependence. In mice, (+)-naloxone did not decrease drinking-in-the-dark and only modestly inhibited dependence-driven consumption at the highest dose. Tlr4 knockdown in mouse NAc did not decrease drinking in the two-bottle choice continuous or intermittent access tests. However, the latency to ethanol-induced loss of righting reflex increased and the duration decreased in KO versus WT rats. In rat central amygdala neurons, deletion of $T l r 4$ altered $\mathrm{GABA}_{\mathrm{A}}$ receptor function, but not GABA release. Although there were no genotype differences in acute ethanol effects before or after chronic intermittent ethanol exposure, genotype differences were observed after LPS exposure. Using different species and sexes, different methods to inhibit TLR4 signaling, and different ethanol consumption tests, our comprehensive studies indicate that TLR4 may play a role in ethanol-induced sedation and $\mathrm{GABA}_{\mathrm{A}}$ receptor function, but does not regulate excessive drinking directly and would not be an effective therapeutic target.

Key words: (+)-naloxone; chronic intermittent ethanol vapor; drinking-in-the-dark; lipopolysaccharide; operant self-administration; Toll-like receptor 4 knock-out

Significance Statement

Toll-like receptor 4 (TLR4) is a key mediator of innate immune signaling and has been implicated in alcohol responses in animal models and human alcoholics. Members of the Integrative Neuroscience Initiative on Alcoholism (INIA-Neuroimmune) consortium participated in the first comprehensive study across multiple laboratories to test the hypothesis that TLR4 regulates excessive alcohol consumption in different species and different models of chronic, dependence-driven, and binge-like drinking. Although TLR4 was not a critical determinant of excessive drinking, it was important in the acute sedative effects of alcohol. Current research efforts are directed at determining which neuroimmune pathways mediate excessive alcohol drinking and these findings will help to prioritize relevant pathways and potential therapeutic targets.

\section{Introduction}

Gene expression studies have shown strong representation of immune- and inflammatory-related genes in brains from human alcoholics and rodents after chronic alcohol treatment (Liu et al., 2006; Robinson et al., 2014; Crews and Vetreno, 2016). Deletion of immune genes reduced alcohol consumption in mice and pro- 
vided corroborating behavioral validation for several immune mediators that were predicted by the genomic studies (Blednov et al., 2012; Mayfield et al., 2013). In addition, alcohol craving and consumption were positively correlated with elevated plasma levels of inflammatory cytokines in human alcoholics (Leclercq et al., 2012; Leclercq et al., 2014) and immune marker expression in human postmortem brain was correlated with total lifetime alcohol consumption and age of drinking onset (Crews and Vetreno, 2016).

Current research efforts are focused on determining which neuroimmune/inflammatory pathways are important for mediating excessive alcohol drinking. The family of Toll-like receptors (TLRs), in particular TLR4, is a major component of innate immune signaling and has been hypothesized to mediate inflammatory effects of alcohol in the brain (Alfonso-Loeches et al., 2010; Szabo and Lippai, 2014; Alfonso-Loeches et al., 2016). TLR4 activation is triggered through pathogen-derived ligands, such as the bacterial endotoxin lipopolysaccharide (LPS) and endogenous ligands including high mobility group box 1 protein (Vezzani et al., 2011). Acute ethanol exposure activates TLR4 signaling in brain astrocytes and microglia (Blanco et al., 2005; Fernandez-Lizarbe et al., 2013) and chronic ethanol also triggers TLR4-mediated neuroimmune responses (Lippai et al., 2013; Pascual et al., 2015; Alfonso-Loeches et al., 2016).

Some studies have suggested a role for TLR4 in ethanol drinking, although this has not been observed consistently. Systemic injection of LPS (a primary TLR4 ligand) increased voluntary ethanol consumption in mice (Blednov et al., 2011) and elevated plasma levels of LPS, along with increased intestinal permeability, were measured in human alcoholics (Leclercq et al., 2012). Selective knockdown of TLR4 in the CeA or the ventral tegmental area (VTA) (but not the ventral pallidum, VP) decreased binge drinking in alcohol-preferring (P) rats (Liu et al., 2011; June et al., 2015). Although TLR4 deficiency protected against ethanolinduced glial activation and induction of inflammatory mediators, Tlr4 knock-out (KO) mice did not differ from wild-type (WT) mice in chronic ethanol consumption (Alfonso-Loeches et al., 2010; Pascual et al., 2011). The TLR4 antagonist T5342126 decreased drinking and the density of a microglial protein in the $\mathrm{CeA}$ in ethanol-dependent and nondependent mice, but the decreased drinking was apparently due to nonspecific effects (Bajo et al., 2016). Overall, there is strong evidence for activation of TLR4 and other neuroimmune mediators in chronic ethanol exposure, but a direct causal link between TLR4 and alcohol drinking behavior has not been shown.

Members of the Integrative Neuroscience Initiative on Alcoholism (INIA-Neuroimmune) consortium (http://www.iniawest.org/) participated in extensive multidisciplinary studies

This work was supported by the National Institutes of Health (Integrative Neuroscience Initiative on Alcoholism and the National Institute on Alcohol Abuse and Alcoholism Grants U01 AA013517 and AA013498 to M.R., Grants U24 AA015512 and U01 AA013522 to R.L.B., Grant U01 AA013520 to Y.A.B. and R.A.H., Grants U01 AA020926 and P0 AA020683 to R.D.M., Grants U01 AA013523 and AA020893 to A.J.R., Grant AA016654 to A.W.L., and Grant U01 AA020889 to G.E.H.). (GFK). We thank Jillian Benavidez, Mendy Black, Molly Brennan, Carolyn Ferguson, Tali Nadav, Lindsay Cates, and Donghong He for expert technical assistance and Brigitte Kieffer and Jahan Dadgar for providing the EGFP-Cre construct.

The authors declare no competing financial interests.

M.L. Logrip's present address: Department of Psychology, Indiana University-Purdue University Indianapolis, IN

L.F. Vendruscolo's present address: National Institute on Drug Abuse, Intramural Research Program, National Institutes of Health, Bethesda, MD.

G.F. Koob's present address: National Institute on Alcohol Abuse and Alcoholism, National Institutes of Health, Bethesda, MD.

Correspondence should be addressed to R. Adron Harris, Ph.D., Waggoner Center for Alcohol and Addiction Research, The University of Texas at Austin, 2500 Speedway, Austin, TX 78712. E-mail: harris@austin.utexas.edu. DOI:10.1523/JNEUROSCI.2002-16.2016

Copyright $\odot 2017$ the authors $\quad 0270-6474 / 17 / 371140-17 \$ 15.00 / 0$ to test the hypothesis that TLR4 is directly involved in ethanol drinking and other ethanol-related responses. TLR4 signaling was inhibited using the following: (1) null mutant rats lacking the Tlr4 gene, (2) selective knockdown of Tlr4 mRNA in the nucleus accumbens (NAc) of mice using Cre recombinase-mediated Tlr4 gene excision, and (3) injection of the selective TLR4 antagonist (+)-naloxone in C57BL/6J mice. None of these approaches provided consistent evidence that TLR4 regulates ethanol intake in any drinking test in mice or rats. However, there was evidence that TLR4 mediates the acute sedative effects of ethanol. Electrophysiological studies revealed that genetic deletion of Tlr4 did not alter spontaneous GABA release in rat CeA neurons, but altered the kinetics of $\mathrm{GABA}_{\mathrm{A}}$ receptor-mediated IPSCs.

\section{Materials and Methods}

Animals

Rats. A rat line on a Wistar background harboring a nonfunctional Tlr4 gene was produced using transcription activator-like effector nuclease mediated mutagenesis as described previously (Ferguson et al., 2013). This line carries a 13-base pair frame shift mutation in Tlr4 Exon 1 and has a dramatically attenuated response to LPS challenge (Ferguson et al., 2013). Heterozygous breeding pairs were produced at the University of Pittsburgh (Pittsburgh, PA) and shipped to The Scripps Research Institute (La Jolla, CA) and the Indiana University School of Medicine (Indianapolis). WT control and homozygous $\mathrm{KO}\left(\mathrm{Tlr}^{-1-}\right)$ littermates produced from these heterozygous pairs were used at the respective institutions. Offspring were weaned at $\sim 21 \mathrm{~d}$ of age and genotyped as described previously (Ferguson et al., 2013).

Mice. Male 12-week-old C57BL/6J mice (The Jackson Laboratory) were used to investigate the effects of $(+)$-naloxone on ethanol drinking. Mice were housed in groups of four before the drinking tests. Lights were on a reverse $12 \mathrm{~h} \mathrm{light} / 12 \mathrm{~h}$ dark cycle (lights on at 8:00 P.M.). These studies were conducted at The Scripps Research Institute.

Adult male mice with a floxed Tlr 4 gene (i.e., mice with Tlr 4 flanked by LoxP sites, denoted as Tlr $4^{\mathrm{F} / \mathrm{F}}$ ) were generated on a C57BL/6 background as described previously (Sodhi et al., 2012) and used for knockdown studies in the NAc. Original breeders were produced at the University of Pittsburgh and mating pairs were shipped to The University of Texas at Austin. Mice were group-housed $4-5$ to a cage on a $12 \mathrm{~h}$ light/ $12 \mathrm{~h}$ dark cycle (lights on at 7:00 A.M.). Ethanol consumption tests began when the mice were at least 2 months old.

Rats and mice at the different institutions were housed in temperatureand humidity-controlled vivaria with water and food provided ad libitum. All vivaria are approved by the Association for Assessment and Accreditation of Laboratory Animal Care. All procedures adhered to the National Institutes of Health's Guide for the Care and Use of Laboratory Animals and were approved by the institutional animal care and use committees at each site.

\section{LPS injections}

Ethanol-naive adult male Tlr4 KO and WT rats ( $n=4$ per genotype) weighing 479-604 $\mathrm{g}$ at the beginning of the experiment were housed individually on a $12 \mathrm{~h}$ light/12 h dark cycle (lights on at 6:00 A.M.). Baseline body weight and food and water consumption were measured $24 \mathrm{~h}$ before LPS injection. Rats were injected intraperitoneally with 1 $\mathrm{mg} / \mathrm{kg}$ LPS (L3024, Escherichia coli 0111:B4; Sigma-Aldrich) dissolved in saline $30 \mathrm{~min}$ before the start of the dark cycle. Immediately before injection and subsequently every $12 \mathrm{~h}$ for $7 \mathrm{~d}$, body weight and food and water intake were measured. Seven to $10 \mathrm{~d}$ after a single LPS injection, in vitro electrophysiological experiments were performed to assess the acute ethanol effects on CeA GABAergic transmission.

For LPS effects on operant ethanol self-administration, adult male Tlr4 KO and WT rats ( $n=5$ per genotype) weighing $350-375 \mathrm{~g}$ at the beginning of the experiment were housed in groups of two per cage in a temperature-controlled $\left(22^{\circ} \mathrm{C}\right)$ vivarium on a $12 \mathrm{~h} \mathrm{light} / 12 \mathrm{~h}$ reversed dark-light cycle (lights on at 10:00 P.M.). After completing operant ethanol self-administration training (described below), the rats were housed individually, injected with LPS (1 mg/kg, i.p.), and body weight and food/water intake were recorded daily. Ethanol and water self- 
administration testing were performed in 30 min sessions for 14 consecutive days followed by a second LPS injection and 14 more days of testing. Baseline body weight and food and water consumption were measured $24 \mathrm{~h}$ before the first LPS injection.

LPS data are presented as the mean \pm SEM intake in $24 \mathrm{~h}$ (food, water) or the percentage change relative to preinjection baseline (body weight). Raw data (intake or body weight change, in grams, over a $24 \mathrm{~h}$ period) were analyzed using two-way repeated-measures ANOVA with group (Tlr4 KO vs WT) as the between-subjects factor and days since LPS injection as the within-subjects factor. Bonferroni and Newman-Keuls tests were used for post hoc analyses.

\section{Ethanol intake tests in rats}

Two-bottle choice (2BC). Rats were double-housed by sex and genotype (Tlr4 KO vs WT). Lights were on a reverse $12 \mathrm{~h}$ light/12 h dark cycle (lights on at 10:30 P.M.). On postnatal day 85 , male and female rats were transferred from their home cages and singly housed in hanging stainless steel wire-mesh cages for habituation to this environment. Male and female littermate offspring of each genotype were tested using the $2 \mathrm{BC}$ ethanol consumption test beginning on postnatal day 90 . Rats were given ad libitum choice access to $10 \%$ ethanol $(\mathrm{v} / \mathrm{v})$ and water for 5 weeks. Ethanol (grams per kilogram body weight) and water (milliliters per kilogram body weight) consumption were assessed $5 \mathrm{~d}$ /week and body weight (kilograms) was measured $3 \mathrm{~d}$ /week. Ethanol intake was converted to grams of absolute (i.e., corrected for specific gravity) ethanol consumed/kilogram of body weight/day. Due to daily fluctuations in ethanol consumption in all groups, the data for each day were averaged across each week of access. The weekly data were submitted to a $3 \times 2 \times$ 5 (genotype by sex by week) mixed-model ANOVA, with genotype and sex as the between-subjects factors and week as the within-subjects factor.

Operant self-administration. Adult male Tlr4 KO $(n=12)$ and WT ( $n=13$ ) rats weighing $250-350 \mathrm{~g}$ at the beginning of the experiment were housed in groups of two per cage in a temperature-controlled $\left(22^{\circ} \mathrm{C}\right)$ room on a reverse $12 \mathrm{~h}$ light $/ 12 \mathrm{~h}$ dark cycle and the behavioral tests were conducted during the dark phase of the circadian cycle. Self-administration sessions were conducted in standard operant conditioning chambers (Med Associates). Animals were first trained to selfadminister $10 \%$ ethanol (w/v) and water solutions until stable responses were maintained. The rats were subjected to an overnight session in the operant chambers with access to 1 lever (right lever) that delivered water [fixed ratio 1 (FR1) schedule of reinforcement, i.e., each operant response was reinforced with $0.1 \mathrm{ml}$ of the solution]. Food was available ad libitum during training. After $1 \mathrm{~d}$ off, the rats were subjected to a $2 \mathrm{~h}$ session (FR1) for $1 \mathrm{~d}$ and a $1 \mathrm{~h}$ session (FR1) the next day, with 1 lever delivering ethanol (right lever). All of the subsequent sessions lasted 30 min and 2 levers were available (left lever: water; right lever: ethanol) until stable levels of intake were reached. Upon completion of this procedure, the animals were allowed to self-administer $10 \%(\mathrm{w} / \mathrm{v})$ ethanol and water (FR1). Self-administration was analyzed by two-way repeatedmeasures ANOVA with group as the between-subjects factor and session as the within-subjects factor.

Chronic intermittent ethanol (CIE). Rats were made dependent by chronic, intermittent exposure to ethanol vapor for 5-7 weeks as described previously (O’Dell et al., 2004; Gilpin et al., 2008). They underwent cycles of $14 \mathrm{~h}$ on [blood ethanol concentrations (BECs) during vapor exposure ranged between 150 and $250 \mathrm{mg} \%$ ] and $10 \mathrm{~h}$ off, during which behavioral testing for acute withdrawal and operant selfadministration (see below) occurred (i.e., 6-8 h after vapor was turned off when brain and BECs are negligible; Gilpin et al., 2009). In this model, rats exhibit somatic withdrawal signs and negative emotional symptoms reflected by anxiety-like responses and elevated brain reward thresholds (Schulteis et al., 1995; Roberts et al., 2000; Valdez et al., 2002; Rimondini et al., 2003; O'Dell et al., 2004; Sommer et al., 2007; Zhao et al., 2007; Edwards et al., 2012; Vendruscolo and Roberts, 2014). For the electrophysiology experiments, the rats were kept in the vapor chambers until they were killed.

Operant self-administration during CIE vapor exposure. Behavioral testing occurred three times per week. The rats were tested for $10 \%$ ethanol (and water) self-administration on an FR1 schedule of reinforcement in 30 min sessions. Operant self-administration on an FR1 schedule requires minimal effort by the animal to obtain the reinforcement and herein was considered a measure of intake. Ethanol self-administration data were analyzed by two-way repeated-measures ANOVA with group ( Tlr4 KO vs WT) as the between-subjects factor and session as the withinsubjects factor. Because the same rats were used to measure predependent versus dependent ethanol self-administration, the number of lever presses for ethanol (last six sessions before ethanol vapor exposure) were averaged and compared with the average lever presses across six self-administration sessions during ethanol vapor exposure. Data were analyzed using two-way mixed models ANOVA with group as the between-subjects factor and time (predependent vs dependent) as the within-subjects factor.

\section{Ethanol intake tests in mice}

Drinking-in-the-dark (DID). The DID procedure is a binge-like drinking model, which capitalizes on the circadian rhythm in drinking and uses a discrete time of exposure to ethanol to optimize pharmacologically significant ethanol drinking (Rhodes et al., 2005; Rhodes et al., 2007; Thiele et al., 2014). Three factors are important in this model: (1) providing access to ethanol a few hours into the dark cycle, (2) not allowing access to water when ethanol is offered, and (3) using genetically predisposed mice. BECs in C57BL/6J mice in this model are reliably $>100 \mathrm{mg} \%$ after the final drinking period and motor impairments are detected using the accelerating rotarod and balance beam tests (Rhodes et al., 2005, 2007). C57BL/6 J mice were individually housed 1 week before testing. On day 1 , starting $3 \mathrm{~h}$ after lights off (11:00 A.M.), water bottles were replaced with drinking tubes containing $20 \%$ ethanol in tap water for $2 \mathrm{~h}$. On day 4 , the ethanol bottles remained for $4 \mathrm{~h}$, with intakes recorded after both 2 and $4 \mathrm{~h}$. Immediately after removal of the ethanol bottles, tail blood was sampled to measure BEC. On day 4 , mice were injected with $(+)$ naloxone $(0,30$, or $60 \mathrm{mg} / \mathrm{kg} ; n=8$ per group) $30 \mathrm{~min}$ before the drinking session began (10:30 A.M.) to investigate its acute effects. The following week, saline or $60 \mathrm{mg} / \mathrm{kg}(+)$-naloxone $(n=8$ per group) was injected on all $4 \mathrm{~d}$ of DID testing $30 \mathrm{~min}$ before the drinking sessions to examine subchronic effects. $(+)$-Naloxone was synthesized by E.R. and freshly dissolved in saline and administered intraperitoneally at $0.01 \mathrm{ml} / \mathrm{g}$ body weight. The $\mu$-opioid inactive stereoisomer, $(+)$-naloxone, is a selective TLR4 inhibitor (Hutchinson et al., 2008; Wang et al., 2016). Data were analyzed separately at the 2 and $4 \mathrm{~h}$ time points using one-way ANOVA with $(+)$-naloxone dose as the between-subjects factor.

CIE-2BC. In the CIE-2BC model, excessive ethanol consumption is observed after $2 \mathrm{BC}$ limited-access periods are cycled with chronic passive exposure to ethanol vapor in rats (Vendruscolo and Roberts, 2014) or C57BL/6 J mice (Becker and Lopez, 2004; Finn et al., 2007; Griffin et al., 2009). This has been used to model the motivational aspects of alcohol dependence and the excessive drinking associated with the addicted state. For $15 \mathrm{~d}$ ( $5 \mathrm{~d}$ per week for 3 weeks), $30 \mathrm{~min}$ before the lights turn off (7:30 A.M.), C57BL/6J mice were individually housed for $2 \mathrm{~h}$ with access to 2 drinking tubes containing either $15 \%$ ethanol or water. Ethanol and water consumption during these $2 \mathrm{~h}$ periods were recorded. After this baseline period, mice were divided, based on equal ethanol and water consumptions, into two balanced groups to be exposed to CIE or air in identical vapor chambers. After baseline $2 \mathrm{BC}$ drinking, the CIE group was injected with $1.75 \mathrm{~g} / \mathrm{kg}$ ethanol plus $68 \mathrm{mg} / \mathrm{kg}$ pyrazole (alcohol dehydrogenase inhibitor) and placed in the chambers to receive intermittent vapor for $4 \mathrm{~d}$ (vapor on for $16 \mathrm{~h}$ and off for $8 \mathrm{~h}$ ). After each $16 \mathrm{~h}$ period of vapor, mice were removed and, on the second and fourth days, tail blood was sampled to determine BEC. Target BECs were 175-250 $\mathrm{mg} \%$. After the fourth day of exposure, mice were allowed $72 \mathrm{~h}$ of undisturbed time and were then given $5 \mathrm{~d}$ of $2 \mathrm{~h}$ access to bottles containing $15 \%$ ethanol and water to measure ethanol drinking and preference after vapor exposure. The control group was injected with $68 \mathrm{mg} / \mathrm{kg}$ pyrazole in saline and placed in chambers delivering air for the same periods as the CIE group and received $2 \mathrm{BC}$ testing at the same time as the ethanol vapor group. The vapor/air exposure and $5 \mathrm{~d}$ of $2 \mathrm{BC}$ testing were repeated for a total of 4 rounds of vapor and $2 \mathrm{BC}$ testing before $(+)$-naloxone testing. For the first study, 30 mice ( $n=15$ per group) were administered $(+)$ - 
naloxone $(0,3,10,30,60 \mathrm{mg} / \mathrm{kg})$ in a within-subjects manner $30 \mathrm{~min}$ before 2BC testing (7:00 A.M.). Drug injections were given every 3-4 d. For the second study, 20 mice were used in a between-subject design $(n=$ $4-6$ in 4 groups: control-vehicle, control-60 mg/kg (+)-naloxone, CIEvehicle, CIE-60 mg/kg (+)-naloxone). Mice were injected $30 \mathrm{~min}$ before the $2 \mathrm{BC}$ procedure across $4 \mathrm{~d}$ of testing. Data from the first study were analyzed by two-way repeated-measures ANOVA (group as the between factor; dose as the within factor) and data from the second study were analyzed by three-way repeated-measures ANOVA (group and dose as the between factors; day as the within factor). Significant effects were further investigated using Fisher's protected (P)LSD tests.

$2 B C$ (24 $h$ continuous access). Four weeks after lentiviral Crerecombinase injections in the NAc to knock down Tlr4 selectively (see below), a 2BC protocol was performed as described previously (Blednov et al., 2003). $T l r 4^{\mathrm{F} / \mathrm{F}}$ male mice were allowed to acclimate for 1 week to individual housing. Two drinking bottles (containing water and ethanol) were available continuously to each mouse and bottles were weighed daily. Bottle positions were changed daily to control for position preferences. Mice were weighed every $4 \mathrm{~d}$. After $4 \mathrm{~d}$ of water consumption (both bottles contained water), mice were offered $3 \%$ ethanol $(\mathrm{v} / \mathrm{v})$ versus water for $4 \mathrm{~d}$. The amount of ethanol consumed $(\mathrm{g} / \mathrm{kg}$ body weight per $24 \mathrm{~h}$ ) was calculated for each mouse and these values were averaged for every concentration of ethanol. Immediately after 3\% ethanol, a choice between $6 \%$ ethanol and water was offered for $2 \mathrm{~d}$, followed by $8 \%, 10 \%$, $12 \%, 14 \%$, and finally $16 \%(\mathrm{v} / \mathrm{v})$ ethanol (each concentration was offered for $4 \mathrm{~d}$ ). Throughout the experiment, evaporation/spillage estimates were calculated daily using two bottles (containing water or the appropriate ethanol solution) placed in an empty cage. Data were analyzed by two-way repeated-measures ANOVA followed by Bonferroni post hoc tests.

$2 B C$ ( $24 \mathrm{~h}$ intermittent access). Intermittent (every other day) access to ethanol increases voluntary ethanol consumption in mice (Melendez, 2011). This drinking paradigm was tested in a different group of $T l r 4^{\mathrm{F} / \mathrm{F}}$ male mice 4 weeks after lentivirus injections in the NAc. Mice were given access to a bottle of $15 \%(\mathrm{v} / \mathrm{v})$ ethanol and a bottle of water during $24 \mathrm{~h}$ sessions every other day. The placement of the ethanol bottles was alternated with each drinking session to control for side preferences. The quantity of ethanol consumed was calculated as grams per kilogram body weight per $24 \mathrm{~h}$. Evaporation/spillage estimates were calculated daily from two bottles (containing water or $15 \%$ ethanol solution) placed in an empty cage. Data were analyzed by two-way repeated-measures ANOVA followed by Bonferroni post hoc tests.

\section{Acute behavioral effects}

Ethanol-induced loss of righting reflex (LORR). Adult male Tlr4 $\mathrm{KO}$ and WT rats ( $n=10$ per genotype) weighing 350-400 g were housed in groups of two per cage. Each rat was handled $5 \mathrm{~min} / \mathrm{d}$ for 1 week before beginning the experiment. On test day, the rats were injected with $4 \mathrm{~g} / \mathrm{kg}$ ethanol $(20 \% \mathrm{v} / \mathrm{v}$ in saline, i.p.). After injection, the rat was placed in a supine position on a V-shaped platform. The time to LORR (time between the injection and the moment in which the rat is not able to right himself) and the time of LORR (interval between the loss of ability to flip over onto all four limbs when placed in a supine position and the time when this reflex was successfully demonstrated three consecutive times within $60 \mathrm{~s}$ ) were scored. Data were analyzed using an unpaired $t$ test.

\section{Selective knockdown of TLR4 in mouse NAc}

Lentivirus-mediated knockdown of Tlr4. Tlr $4^{\mathrm{F} / \mathrm{F}}$ male mice received bilateral injections into the NAc with either a vesicular stomatitis virus (VSV-G) pseudotyped lentivirus expressing Cre recombinase fused to an enhanced green fluorescent protein (EGFP) under the control of a cytomegalovirus (CMV) promoter (LV-Cre-EGFP) or an "empty" VSV-G pseudotyped lentivirus vector expressing only the EGFP transgene under a CMV promoter (LV-EGFP-Empty). Virus was produced as described previously (Lasek et al., 2007). Mice were anesthetized by isoflurane inhalation, placed in a model 1900 stereotaxic apparatus (Kopf Instruments), and administered preoperative analgesic (Rimadyl, $5 \mathrm{mg} / \mathrm{kg}$ ). The skull was exposed and bregma and lambda visualized with a dissecting microscope. A digitizer attached to the micromanipulator of the
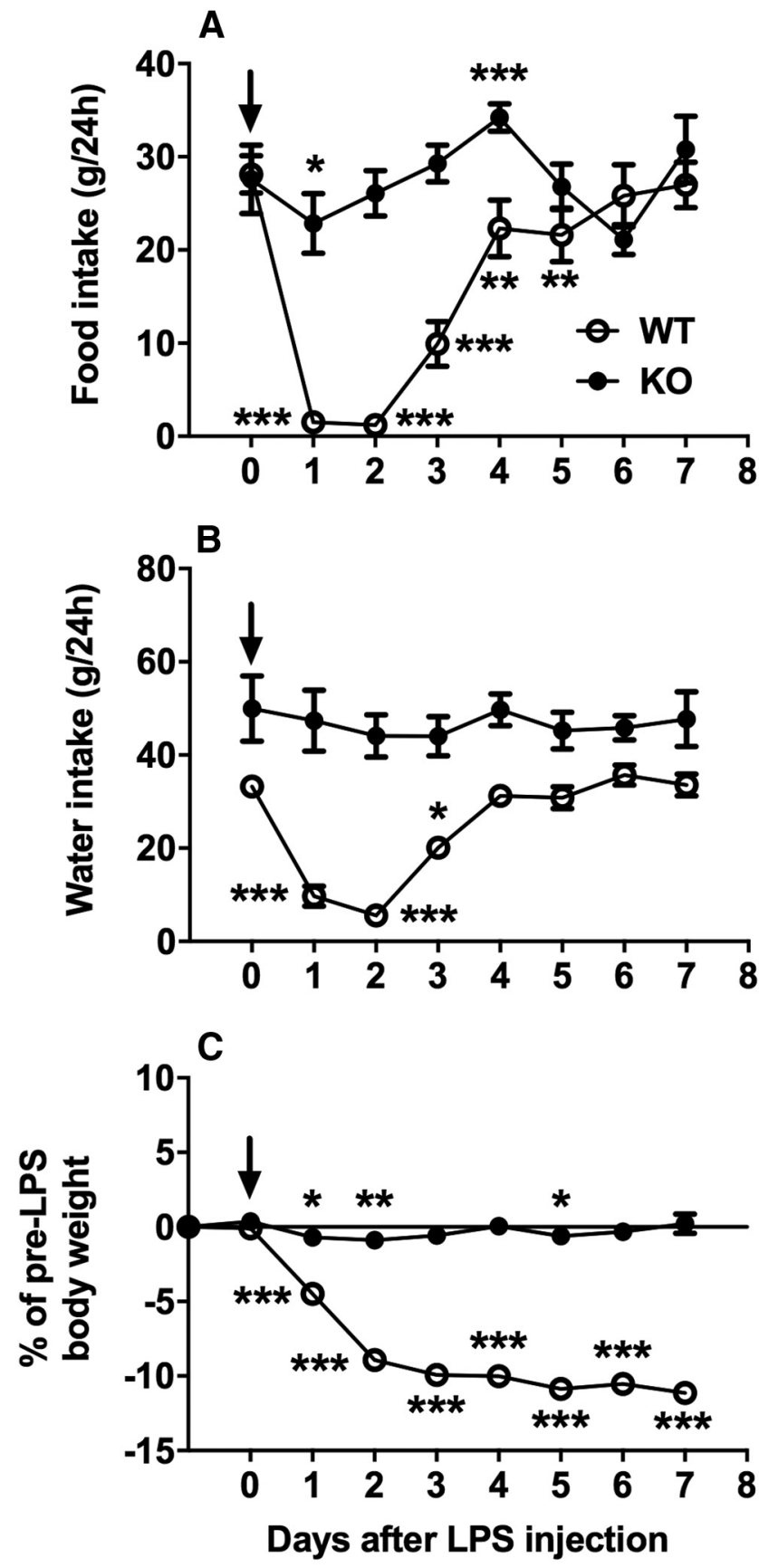

Figure 1. T/r4 KO rats are resistant to LPS-induced toxicity. LPS produced transient reduction of food $(\boldsymbol{A})$ and water $(\boldsymbol{B})$ intake in male WT but not TIr $4 \mathrm{KO}$ rats. The data are presented as mean \pm SEM food and water intake (in grams) in $24 \mathrm{~h}$ periods. Day 0 represents intake measured during the $24 \mathrm{~h}$ before LPS (1 mg/kg, i.p.) injection. C, LPS induced a robust weight loss in WT but not T/r4 KO rats. The data are presented as percentage change relative to preinjection baseline weight (error bars are obscured by the symbols). Data were analyzed by two-way repeated-measures ANOVA followed by Bonferroni post hoc tests; ${ }^{*} p<0.05,{ }^{* *} p<0.01$, ${ }^{* * *} p<0.001$ compared with baseline; $n=4$ per genotype. Arrows indicate injection of LPS (1 $\mathrm{mg} / \mathrm{kg}$, i.p.).

stereotaxic apparatus was used to locate coordinates relative to bregma. Burr holes were drilled bilaterally above the injection sites in the skull using a drill equipped with a \#75 carbide bit (Kopf Instruments). The injection sites targeted the NAc using the following coordinates relative to bregma: anteroposterior (AP) $+1.49 \mathrm{~mm}$, mediolateral $(\mathrm{ML}) \pm 0.9$ $\mathrm{mm}$, and dorsoventral (DV) $-4.8 \mathrm{~mm}$. Injections were performed using a Hamilton $10 \mu \mathrm{l}$ microsyringe (model 1701) and a 30-gauge needle. The needle tip was lowered to the DV coordinate and retracted $0.2 \mathrm{~mm}$. The 

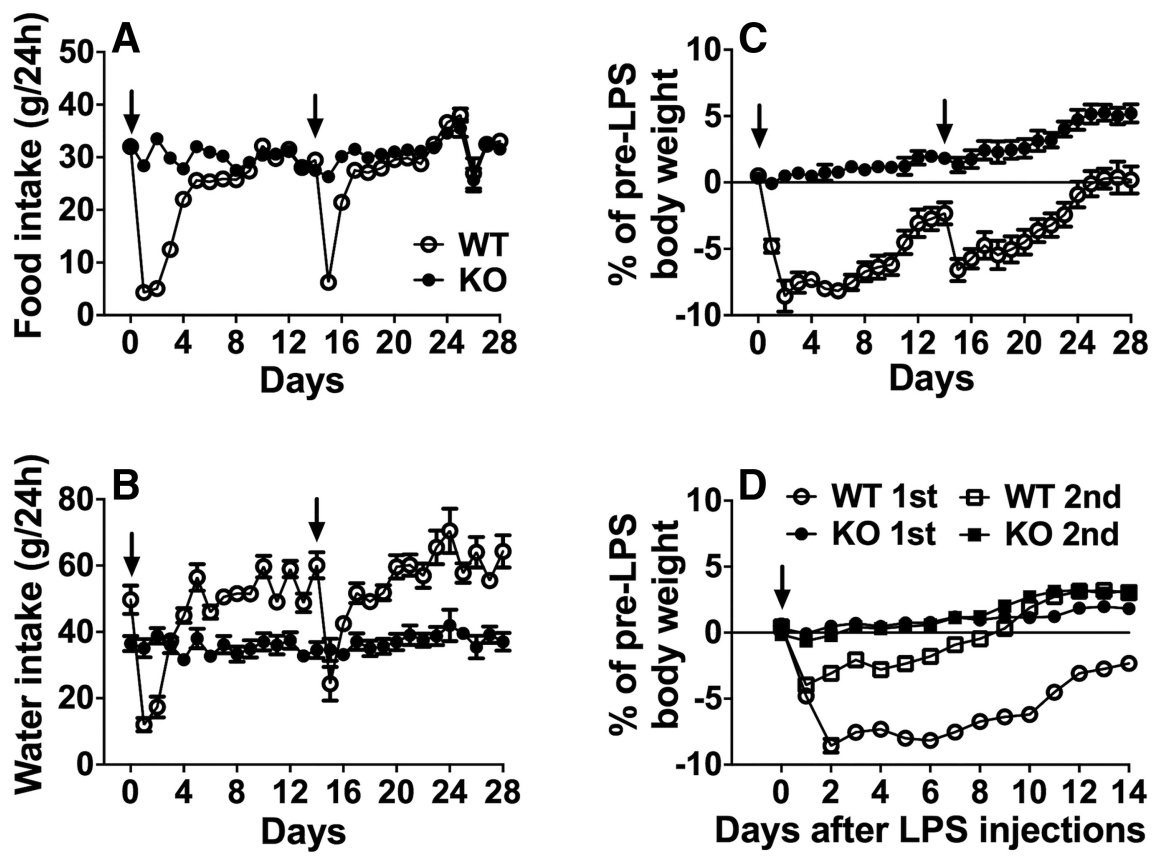

Figure 2. TIr $4 \mathrm{KO}$ rats trained to self-administer ethanol (10\%) are resistant to LPS-induced toxicity. The data are presented as mean \pm SEM of food $(\boldsymbol{A})$ and water $(\boldsymbol{B})$ intake in $24 \mathrm{~h}$ in male WT $(n=5)$ and T/r $4 \mathrm{KO}(n=5)$ rats. Day 0 corresponds to intake for the $24 \mathrm{~h}$ before LPS $(1 \mathrm{mg} / \mathrm{kg}$, i.p.) injection. C, Time course of the change in body weight over $24 \mathrm{~h}$ in male rats. The data are presented as the percentage change relative to the preinjection baseline weight measured before the first LPS injection. $\boldsymbol{D}$, Time course of the change in body weight of LPS-treated WT and KO rats after the first and second LPS injections. LPS-induced changes in body weight are expressed as the percentage change relative to the most recent preinjection weight. In WT rats, paired Student's $t$ test $\left(t_{(4)}=6.0, p<0.01\right)$ showed a significant decrease in loss of body weight $1-4 \mathrm{~d}$ after the second LPS injection $(-3.4 \pm$ $0.5 \%)$ compared with the weight loss after the first LPS injection $(-7.1 \pm 0.7 \%)$. There was no significant difference in the LPS effects between the first and second LPS injections in the T/r4 KO rats. Arrows indicate injection of LPS (1 mg/kg, i.p.).
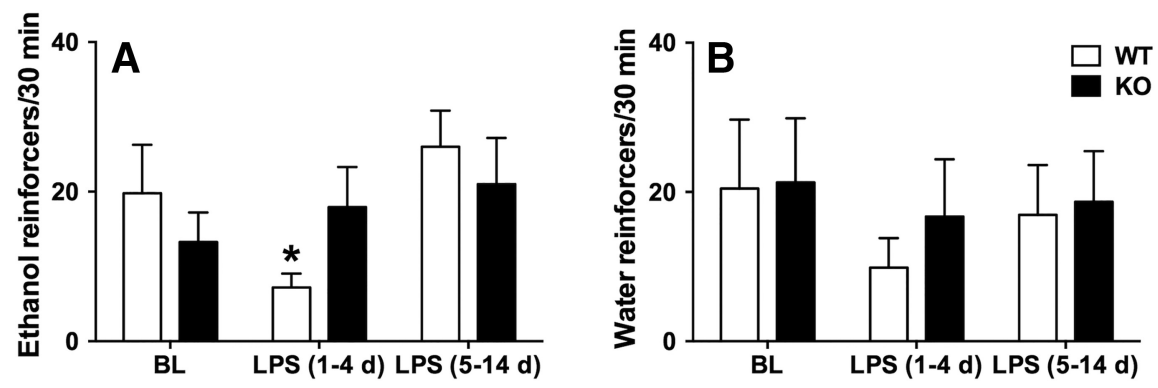

Figure 3. LPS induces transient reduction in ethanol (10\%) self-administration in WT but not T/r4 KO rats. Effect of LPS injections on ethanol $(\boldsymbol{A})$ and water $(\boldsymbol{B})$ self-administration in male WT and TIr4 $\mathrm{KO}$ rats. The data are presented as mean \pm SEM lever presses during 30 min sessions. Baseline (BL) was calculated as the average of the last 4 sessions before each LPS injection. Rats were given two LPS (1 mg/kg, i.p.) injections $14 \mathrm{~d}$ apart and the data from both injections were averaged. The average lever presses $1-4 \mathrm{~d}$ and $5-12 \mathrm{~d}$ after LPS are shown. Data were analyzed by mixed-factorial ANOVA followed by Newman-Keuls posthoc test; ${ }^{*} p<0.05$ compared with $\mathrm{K} 0 ; n=5$ per genotype.

viral solution $\left(1.0 \mu \mathrm{l}\right.$ with titer of $\sim 3 \times 10^{7} \mathrm{pg}$ gag antigen $/ \mathrm{ml}$ in PBS, PBS) was injected into each site at a rate of $200 \mathrm{nl}$ per min. After each injection, the syringe was left in place for 5 min before being retracted over a period of $3 \mathrm{~min}$. Incisions were closed with tissue adhesive (Vetbond; $3 \mathrm{M})$. Mice were housed individually after surgery and given a 4-week recovery period before starting the ethanol drinking tests. Separate groups of mice were used for each $2 \mathrm{BC}$ test.

RNA isolation. Approximately half of the treated $T l r 4^{\mathrm{F} / \mathrm{F}}$ mice were killed within $24 \mathrm{~h}$ of completing the drinking tests. The brains were quickly removed, flash frozen in liquid nitrogen, and later frozen in optimal cutting temperature medium (VWR) in isopentane on dry ice and stored at $-80^{\circ} \mathrm{C}$. Brains were transferred to a cryostat set at $-6^{\circ} \mathrm{C}$ for at least $1 \mathrm{~h}$ before sectioning. Sections $(300 \mu \mathrm{m})$ were collected from +1.80 to $+0.60 \mathrm{~mm}(\mathrm{AP})$ relative to bregma and transferred to glass slides that had been precooled on dry ice. Micropunch sampling was performed on a frozen stage $\left(-25^{\circ} \mathrm{C}\right)$ using a dual fluorescent protein flashlight (Nightsea) and the stereotaxic atlas of Paxinos and Franklin (2004) to confirm EGFP expression and the anatomical location of the injection site, respectively. Microdissection punches (Stoelting) with an inner diameter of $0.75 \mathrm{~mm}$ were used to obtain samples of NAc core and shell. This inner diameter corresponded to the viral spread around the injection site and minimized contamination from other tissue. Punches were taken bilaterally from four $300 \mu \mathrm{m}$ sections and stored at $-80^{\circ} \mathrm{C}$ until RNA extraction. All equipment and surfaces involved in the collection of tissue were treated with $100 \%$ ethanol and RNaseZap (Life Technologies) to prevent RNA degradation. Total RNA was extracted using the MagMAX-96 for Microarrays Total RNA Isolation Kit (Life Technologies) according to the manufacturer's instructions. Yields and purity were assessed using a NanoDrop 8000 (Thermo Fisher Scientific), and quality of the total RNA preparation was determined using the Agilent 2200 TapeStation.

Quantitative real-time PCR. To verify Tlr4 mRNA knockdown, single-stranded cDNA was synthesized from total RNA using the TaqMan High Capacity RNA-to-cDNA kit (Life Technologies). After reverse transcription, quantitative real-time PCR ( $\mathrm{qPCR}$ ) was performed in triplicate using TaqMan Gene Expression Assays together with the TaqMan Gene Expression Master Mix (Life Technologies) per the manufacturer's instructions. The TaqMan Gene Expression assays used were Tlr4 (Mm00445273_ml) and enhanced GFP (Mr04097229_mr). Gapdh (Mm99999915_g1) was used as a reference gene and relative mRNA levels were determined using the $2^{-\Delta \Delta \mathrm{CT}}$ method (Schmittgen and Livak, 2008). Gapdh was used as the endogenous control because of its stable expression across samples. Reactions were performed in a CFX384 Real-Time PCR Detection System (Bio-Rad) and data collected using Bio-Rad CFX Manager.

Target site verification. The other half of the $T l r 4^{\mathrm{F} / \mathrm{F}}$-treated mice were killed within $24 \mathrm{~h}$ of completing the drinking tests and transcardially perfused with PBS, $\mathrm{pH} 7.4$, followed by $4 \%$ paraformaldehyde (PFA). Brains were harvested, postfixed for $24 \mathrm{~h}$ in $4 \% \mathrm{PFA}$ at $4^{\circ} \mathrm{C}$, and cryoprotected for $24 \mathrm{~h}$ in $20 \%$ sucrose in $\mathrm{PBS}$ at $4^{\circ} \mathrm{C}$. Brains were placed in molds containing optimal cutting temperature compound (VWR) and frozen in isopentane on dry ice. The brains were equilibrated in a -12 to $-14^{\circ} \mathrm{C}$ cryostat (Thermo Fisher Scientific) for at least $1 \mathrm{~h}$ and coronal $40 \mu \mathrm{m}$ sections of the NAc were placed in sterile PBS. Serial sections $(40 \mu \mathrm{m})$ of NAc (AP +2.00 to $0.00 \mathrm{~mm}$ ) were mounted on slides with DAPI mounting medium (Vector Laboratories) and visualized using a Zeiss Axiovert 200M Fluorescent Microscope equipped with a $10 \times$ objective to assess the location of the injection site. Quality of injection was scored quantitatively based on the strength of EGFP viral expression, injection location relative to target, and the spread of the virus. The injection was considered on target if the virus covered at least one-third of the NAc.

Whole-cell voltage-clamp electrophysiology

Slice preparation. Male WT and Tlr4 KO rats (used previously for operant self-administration testing) were made ethanol dependent by CIE vapor 
A

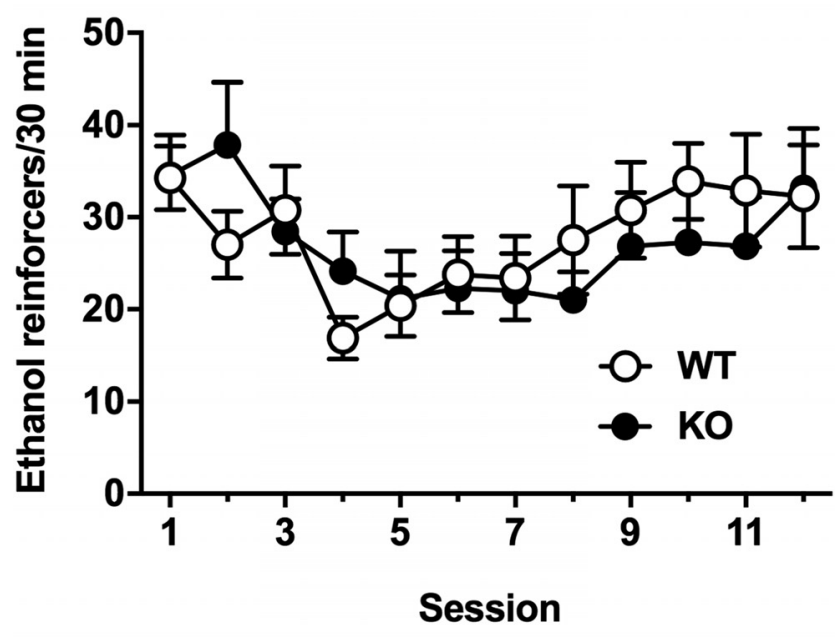

B

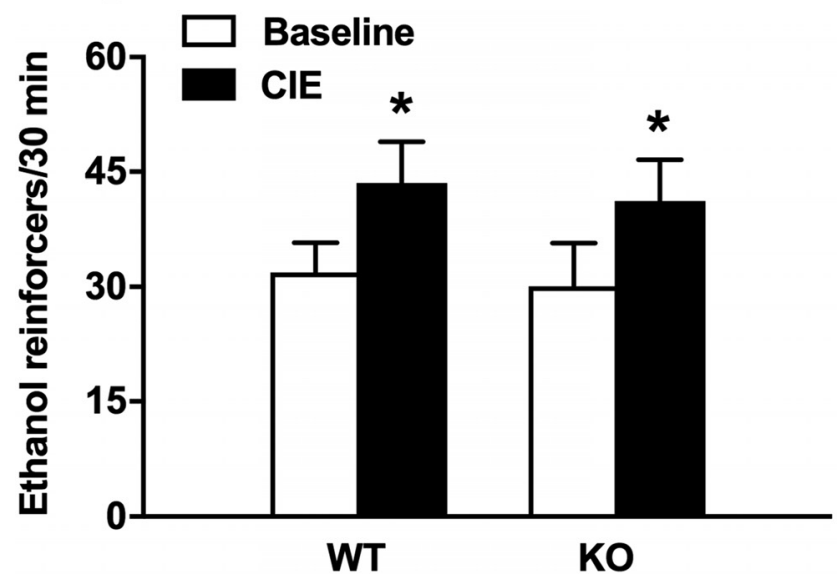

Figure 4. There was no effect of genotype on ethanol self-administration in WT or TIr4 KO rats before or after dependence. $\boldsymbol{A}$, Male WT and TIr4 KO rats do not differ in ethanol (10\%) self-administration before ethanol vapor exposure. The data are presented as mean \pm SEM lever presses during 30 min sessions. Data were analyzed by two-way repeated-measures ANOVA with group as the between-subjects factor and session as the within-subjects factor. $\boldsymbol{B}$, Male WT and T/r4 K0 rats do not differ in ethanol (10\%) self-administration after CIE exposure. Ethanol-dependent rats underwent cycles of $14 \mathrm{~h}$ on (BEC: $146.8 \pm 3.6 \mathrm{mg} \%$ ) and $10 \mathrm{~h}$ off. The same rats were used to measure predependent versus postdependent ethanol selfadministration. For baseline, the number of lever presses for ethanol (last six sessions before ethanol vapor exposure) was averaged and compared with the average number of lever presses over six self-administration sessions during CIE exposure. The data are presented as mean \pm SEM lever presses during 30 min sessions. Data were analyzed using two-way ANOVA with group as the between-subjects factor and time (predependent vs dependent) as the withinsubjects factor ( $n=8$ for WT and $n=7$ for K0, ${ }^{*} p<0.05$ compared with baseline).

exposure as described earlier and kept in the vapor chambers until time for electrophysiological studies. BECs were measured once or twice per week by tail bleeding and again before euthanasia. The mean BEC of all ethanol-exposed animals was $173.0 \pm 21 \mathrm{mg} / \mathrm{dl}$. Slices were prepared from 14 naive control, CIE WT, and Tlr4 KO rats (425-595 g) as described previously (Gilpin et al., 2011; Cruz et al., 2012). Briefly, rats were anesthetized using $3-5 \%$ isoflurane, rapidly decapitated, and the brains placed in ice-cold high-sucrose solution, $\mathrm{pH}$ 7.3-7.4, containing the following (in mM): sucrose (206), $\mathrm{KCl}$ (2.5), $\mathrm{CaCl}_{2}$ (0.5), $\mathrm{MgCl}_{2}$ (7), $\mathrm{NaH}_{2} \mathrm{PO}_{4}$ (1.2), $\mathrm{NaHCO}_{3}$ (26), glucose (5), and HEPES (5). Coronal brain slices $(300 \mu \mathrm{m})$ were cut on a vibrating microtome (Leica VT1000S) and transferred to an oxygenated $\left(95 \% \mathrm{O}_{2} / 5 \% \mathrm{CO}_{2}\right)$ artificial CSF (aCSF) solution containing the following (in mM): $\mathrm{NaCl}(130), \mathrm{KCl}$ (3.5), $\mathrm{CaCl}_{2}$ (2), $\mathrm{NaH}_{2} \mathrm{PO}_{4}$ (1.25), $\mathrm{MgSO}_{4}$ (1.5), $\mathrm{NaHCO}_{3}$ (24), and glu- cose (10). Slices were incubated $\left(30 \mathrm{~min} ; 35-37^{\circ} \mathrm{C}\right)$ and then equilibrated at room temperature for $30 \mathrm{~min}$. For each recording, a slice was placed in a recording chamber mounted on the stage of an upright microscope (Olympus BX50WI) and perfused $(2-5 \mathrm{ml} / \mathrm{min}$ ) with continuously oxygenated aCSF at room temperature.

Electrophysiological recording. Medial subdivision CeA neurons $(n=84)$ were visualized using infrared differential interference contrast (IR-DIC) optics, a CCD camera (EXi Aqua and ROLERA-XR; QImaging; Gilpin et al., 2011; Cruz et al., 2012) and a w60 or w40 water-immersion objective (Olympus Scientific Solutions). Recordings were performed in a gap-free acquisition mode with a sampling rate per signal of $10 \mathrm{kHz}$ and low-pass filtered at $10 \mathrm{kHz}$ using a Multiclamp 700B amplifier and Digidata $1440 \mathrm{~A}$ and pClamp 10 software (Molecular Devices). Borosilicate glass patch pipettes (3-6 M $\Omega$ ) (Warner Instruments) were filled with an internal solution containing the following (in mM): $\mathrm{KCl}$ (145), EGTA (5), $\mathrm{MgCl}_{2}$ (5), HEPES (10), Na-ATP (2), and Na-GTP (0.2). Spontaneous IPSCs (sIPSCs) mediated by $\mathrm{GABA}_{\mathrm{A}}$ receptors were isolated by adding glutamate receptor blockers 6,7-dinitroquinoxaline-2,3-dione (DNQX, $20 \mu \mathrm{M}$; Tocris Bioscience) and DL-2-amino-5-phosphonovalerate (AP-5, $30 \mu \mathrm{M}$; Tocris Bioscience) and the $\mathrm{GABA}_{\mathrm{B}}$ receptor antagonist CGP55845A ( $1 \mu \mathrm{M}$; Sigma-Aldrich) directly to the aCSF. GABAergic miniature IPSCs (mIPSCs) were isolated using glutamatergic and $\mathrm{GABA}_{\mathrm{B}}$ receptor blockers and $0.5 \mu \mathrm{M}$ tetrodotoxin (Biotum). All drugs were applied by bath superfusion.

Cells were clamped at $-60 \mathrm{mV}$ and recordings showing a series resistance $>15 \mathrm{M} \Omega$ or a $>20 \%$ change in series resistance, as monitored with a $10 \mathrm{mV}$ pulse, were excluded. s/mIPSC frequency, amplitude, and kinetics were analyzed using semiautomated threshold-based mini detection software (Mini Analysis; Synaptosoft) and inspected visually. Only s/mIPSCs with amplitude $>5 \mathrm{pA}$ were accepted for analysis and final averages of s/mIPSC characteristics were derived from a minimum time interval of $2-5 \mathrm{~min}$. GraphPad Prism 5.0 software was used for all statistical analyses. The s/mIPSC data were evaluated with cumulative probability analysis and statistical significance was determined using the Kolmogorov-Smirnov nonparametric two-sample test (Van der Kloot, 1991), with $p<0.05$ considered significant. To assess whether differences in ethanol's effects on s/mIPSCs result from the treatment (naive, ethanoldependent, and LPS-injected) and/or genotype (WT and Tlr4 KO rats), twoway ANOVAs of the normalized values were performed (mean values of s/mIPSC characteristics during ethanol application divided by the baseline values). When appropriate, Bonferroni post hoc tests were used to assess significance between treatments. All data are presented as mean \pm SEM and $n$ refers to the number of neurons. One to five neurons were recorded per animal and all electrophysiological measures were obtained by pooling data from at least three animals per experimental group.

\section{Results}

\section{Lack of LPS effects in Tlr4 KO rats}

Tlr4 KO ethanol-naive rats are resistant to LPS-induced toxicity We monitored reductions in food intake (anorexia), water intake (adipsia), and body weight as signs of LPS-induced "sicknesslike” behavior (McCarthy et al., 1984; Cross-Mellor et al., 2000; van Heesch et al., 2013) in naive and ethanol self-administering Tlr4 KO and WT rats. Baseline measures of body weight or food and water consumption did not differ in KO and WT rats. In naive rats, LPS $(1 \mathrm{mg} / \mathrm{kg}$, i.p.) caused a transient reduction of food intake in WT, but not Tlr4 $\mathrm{KO}$ rats (Fig. 1A). There were significant main effects of LPS $\left(F_{(7,42)}=60.7, p<0.0001\right)$ and genotype $\left(F_{(1,42)}=13.7, p<0.01\right)$ on food intake and an interaction between the factors $\left(F_{(7,42)}=30.2, p<0.001\right)$. Profound anorexia occurred within $24 \mathrm{~h}$ after injection in WT rats, which persisted for at least $48 \mathrm{~h}(28.1 \pm 2.0 \mathrm{~g}$ consumed $24 \mathrm{~h}$ before LPS vs $1.2 \pm 0.8 \mathrm{~g}$ after LPS). WT rats gradually increased their food intake, reaching pre-LPS consumption levels by the sixth postinjection day $(25.8 \pm 3.4 \mathrm{~g})$. In Tlr4 KO rats, LPS caused a transient reduction in food intake (from $27.6 \pm 3.7 \mathrm{~g}$ to $22.9 \pm 3.2 \mathrm{~g}$ ) after $24 \mathrm{~h}$, followed by increased food intake on the fourth postinjection day $(34.2 \pm 1.5 \mathrm{~g})$. 

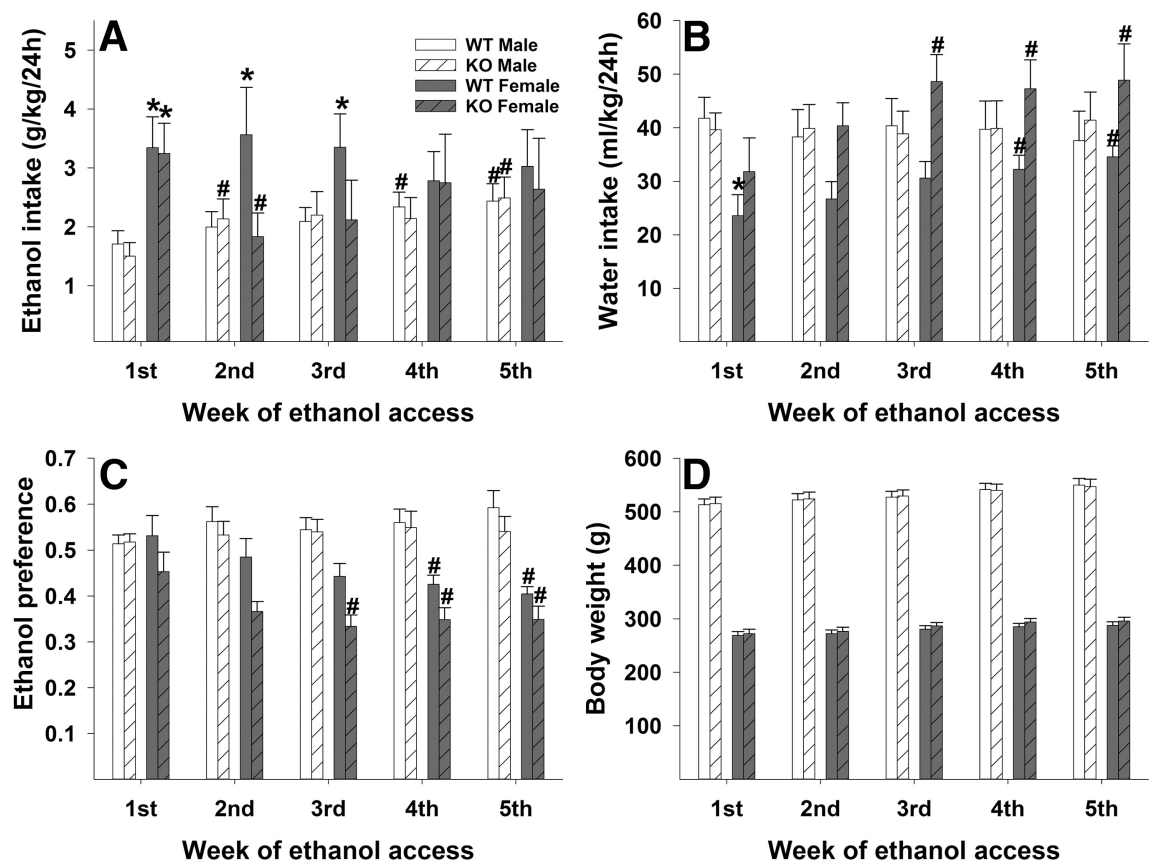

Figure 5. $2 \mathrm{BC}$ ethanol intake in male and female WT and T/r4 K0 rats. $\boldsymbol{A}$, Ethanol (10\%) intake $(\mathrm{g} / \mathrm{kg} / 24 \mathrm{~h}),(\boldsymbol{B})$ water intake $(\mathrm{ml} / \mathrm{kg} / 24 \mathrm{~h}),(\boldsymbol{C})$ ethanol preference, and $(\boldsymbol{D})$ body weight $(\mathrm{g})$ in male and female WT and T/r4 KO rats during $2 \mathrm{BC}$ drinking sessions measured over 5 weeks. The data are presented as mean \pm SEM. Data were analyzed using $2 \times 2 \times 5$ (genotype by sex $\times$ week) mixed ANOVAs (WT male, $n=23$; WT female, $n=16$; K0 male, $n=15$; KO female, $n=11$ ). *Significant $(p<0.05)$ difference between male and female rats within genotype; \#significant $(p<0.05)$ difference between week 1 and a subsequent week for the respective sex within genotype.

LPS reduced water intake in WT rats only (Fig. 1B); this effect peaked on the second postinjection day, with drinking levels returning to baseline by the fourth postinjection day. There were main effects of LPS on water intake $\left(F_{(7,42)}=7.1, p<0.001\right)$ and a significant interaction between LPS and genotype $\left(F_{(7,42)}=4.8\right.$, $p<0.001)$, but the main effect of genotype did not reach significance $(p=0.05)$. Reductions in food and water intake in WT rats were accompanied by significant weight loss, a pattern not observed in KO rats. LPS produced weight loss in WT rats during the first 3 postinjection days, reaching a peak loss of $10 \%$ body weight (Fig. $1 C$ ) (main effects of LPS $\left(F_{(7,42)}=88.2, p<0.001\right.$ ) and genotype $\left(F_{(7,42)}=79.6, p<0.001\right)$ and an interaction between the factors $\left(F_{(7,42)}=73.6, p<0.001\right)$. Body weight then stabilized and the resumption of food intake was associated with the reappearance of normal diurnal fluctuations in body weight when measured every $12 \mathrm{~h}$, similar to Tlr4 KO rats (data not shown). Although a slight reduction in body weight was also observed in the 24-48 h after LPS injection in Tlr4 KO rats, its magnitude was $<25 \%$ of that observed in WT $(\sim 2.5 \%$ absolute weight loss). The resistance of Tlr4 KO rats to LPS-induced "sickness-like behavior" provides behavioral and functional validation that the Tlr4 gene had been deleted.

Tlr4 KO rats trained to self-administer ethanol are resistant to LPS-induced toxicity

Similar to naive rats, there were no significant differences in baseline body weight or water and food intake in the WT and Tlr4 KO rats trained to self-administer 10\% ethanol. LPS injections (14 d apart) significantly $(p<0.001)$ reduced food intake in WT but not KO ethanol-trained rats (Fig. $2 A$ ). Two-way repeated-measures ANOVA showed main effects of LPS $\left(F_{(4,32)} 63.9, p<0.001\right)$ and genotype $\left(F_{(1,32)}=8.4, p<0.05\right)$ on food intake, as well as an interaction between the factors $\left(F_{(4,32)}=43.8, p<0.001\right)$. Al- though water intake was reduced after both LPS injections in WT rats, the intake over the $4 \mathrm{~d}$ period after LPS was reduced significantly only after the first injection (Fig. 2B), suggesting the development of tolerance to its effects. There were no effects of LPS injections on water intake in Tlr4 KO rats. There were main effects of LPS on water consumption $\left(F_{(4,32)}=5.1\right.$, $p<0.001)$ and an interaction between LPS and genotype $\left(F_{(4,32)}=4.0, p<\right.$ $0.001)$ without a main effect of genotype.

In WT rats, two LPS injections induced a significant loss in body weight measured over a $4 \mathrm{~d}$ period after each injection (Fig. 2C). Two-way repeatedmeasures ANOVA showed main effects of LPS $\left(F_{(4,32)}=35.8, p<0.001\right)$ and genotype $\left(F_{(1,32)}=68.4, p<0.001\right)$ and an interaction between the factors $\left(F_{(4,36)}=17.1, p<0.001\right)$. LPS injections had no effect on the body weight of Tlr4 KO rats (Fig. 2C). Because there was not a full recovery in body weight after the first LPS injection in WT rats, we calculated LPS-induced loss in body weight by comparing the weight during days 1-4 after injection to the weight at the time of the most recent injection. The second LPS injection induced a significantly $(p<0.05)$ less pronounced reduction of body weight $(-3.4 \pm 0.5 \%$ after the second LPS injection vs $-7.1 \pm 0.7 \%$ after the first injection) and faster recovery in WT rats (Fig. 2D), suggesting the development of tolerance to its effects.

\section{LPS induces a transient reduction in ethanol self-administration} in WT, but not Tlr4 KO rats

At the end of self-administration training, the baseline lever presses for $10 \%$ ethanol were $19.8 \pm 6.6$ for WT and $13.3 \pm 4.1$ for KO rats. LPS ( $1 \mathrm{mg} / \mathrm{kg}$, i.p.) was injected $30 \mathrm{~min}$ before the next session and rats were tested for ethanol and water selfadministration in 30 min sessions for 14 consecutive days, followed by a second LPS injection and 14 more days of testing. Data after both LPS injections were averaged. A mixed-factorial ANOVA with genotype (Tlr4 $\mathrm{KO}$ vs WT) as the between-subjects factor and time point (baseline, 1-4 d post-LPS, and 5-14 d post-LPS) as the within-subjects factor showed a significant effect of time point $\left(F_{(1,8)}=7.5 ; p<0.01\right)$ and genotype $\times$ time point interaction $\left(F_{(2,8)}=5.6 ; p<0.05\right)$. A Newman-Keuls post hoc test showed that LPS treatment reduced operant responding for ethanol in the WT group $(p<0.05)$ for 4 consecutive days after the injections (Fig. $3 A$ ). No genotype differences were found 5-14 d after LPS injections. A mixed-factorial ANOVA of the water self-administration data showed a significant effect of time point $\left(F_{(1,8)}=7.5 ; p<0.01\right)$, but no difference in the genotype $\times$ time point interaction (Fig. $3 B$ ).

\section{Lack of evidence for a role of TLR4 in ethanol consumption}

No genotype differences in ethanol self-administration by WT or Tlr4 KO rats before or after dependence

Although there was no significant genotype effect on baseline responses in the ethanol self-administration test above, we compared operant responding before and after ethanol dependence specifically 
in both genotypes. Figure $4 A$ shows ethanol self-administration in WT and Tlr4 KO rats before ethanol vapor exposure (predependence). Operant self-administration of $10 \%$ ethanol varied over time (session effect: $\left.F_{(11,143)}=3.3, p<0.0005\right)$, but there were no genotype or genotype $\times$ time differences. After CIE vapor exposure (after dependence), there were also no differences in self-administration, with both WT and Tlr4 $\mathrm{KO}$ rats showing similar increases in intake $\left(F_{(1,13)}=12.3, p<0.005\right.$; Fig. $\left.4 B\right)$.

\section{$2 B C$ ethanol intake in male and female}

WT vs Tlr4 KO rats

We then compared sexes and genotypes in a 2BC chronic drinking paradigm (WT: males, $n=23$; females, $n=16$; Tlr 4 KO: males, $n=$ 15 ; females, $n=11$ ). The omnibus mixed ANOVA of the ethanoldrinking data revealed a marginally significant 3 -way (genotype $\times$ sex $\times$ week) interaction for $10 \%$ ethanol $(\mathrm{v} / \mathrm{v})$ intake $\left(F_{(4,244)}=2.4\right.$, $p=0.05)$. There was a significant two-way (sex $\times$ week) interaction $\left(F_{(4,244)}=3.3, p=0.01\right)$ and a marginally significant main effect of $\operatorname{sex}\left(F_{(1,61)}=4.0, p=0.05\right)$. As seen in Figure $5 A$, female rats drank more ethanol initially than male rats. This effect was observed for the Tlr4 KO rats only during the first week of ethanol access $\left(F_{(1,25)}=\right.$ $11.7, p<0.01)$, whereas the WT rats displayed this effect across the first 3 weeks of ethanol access $\left(F_{(1,38)}>4.5, p<0.05\right)$. There were also changes in ethanol intake across weeks; specifically, WT male rats displayed significant $(p<0.05)$ increases between week 1 versus week 4 and week 1 versus week 5 , whereas Tlr4 $\mathrm{KO}$ male rats displayed significant $(p<0.05)$ increases between week 1 versus week 2 and week 1 versus week 5 . There was a significant decrease in ethanol intake by female Tlr4 $\mathrm{KO}$ rats between weeks 1 and 2. The omnibus mixed ANOVA of the water-drinking data revealed a significant twoway $(\operatorname{sex} \times$ week $)$ interaction $\left(F_{(4,244)}=8.5, p<0.001\right)$ and a significant main effect of week $\left(F_{(4,244)}=6.7, p<0.001\right)$. As shown in Figure $5 B$, male rats initially drank more water than females, with the effect reaching significance $(p<0.05)$ in the WT, but not Tlr4 KO, rats during week 1 . In addition, a modest but significant $(p<0.05)$ increase across weeks was observed in both the female Tlr4 KO (week 1 vs week 4 and week 1 vs week 5) and WT (week 1 vs week 3 , week 1 vs week 4 , and week 1 vs week 5) rats. The omnibus mixed ANOVA of the ethanol preference data revealed a significant two-way ( $\operatorname{sex} \times$ week) interaction $\left(F_{(4,244)}=12.6, p<0.001\right)$ and significant main effects of week $\left(F_{(4,244)}=2.9, p<0.05\right)$ and $\operatorname{sex}\left(F_{(1,61)}=22.4, p<\right.$ $0.001)$. However, the main effect of genotype regarding ethanol preference did not reach significance $(p=0.06)$. Female WT and KO rats displayed decreased ethanol preference across weeks $4-5$ and 3-5, respectively, compared with the first week (Fig. 5C). The omnibus mixed ANOVA of the body weight data revealed a significant two-way (sex $\times$ week) interaction $\left(F_{(4,244)}=8.5, p<0.001\right)$, along with significant main effects of week $\left(F_{(4,244)}=6.7, p<0.001\right)$ and $\operatorname{sex}\left(F_{(1,61)}=505.5, p<0.001\right)$. As seen in Figure $5 D$, female rats weighed significantly less than male rats, with no differences observed for genotype.

No significant effect of $(+)$-naloxone on DID in C57BL/6J mice We examined the effect of pharmacological inhibition of TLR4 signaling in mice using a binge-like drinking model. (+)Naloxone treatment did not alter ethanol (20\%) intake (Fig. 6A) or BEC measured on drinking day 4 of the DID test. There was no overall effect of $(+)$-naloxone at $2 \mathrm{~h}\left(F_{(2,21)}=1.4, p=0.3\right)$ or $4 \mathrm{~h}$ $\left(F_{(2,21)}=0.1, p=0.9\right)$, nor was there an effect on BEC measured at $4 \mathrm{~h}\left(F_{(2,21)}=0.4, p=0.7\right)$. BECs for vehicle-treated, $30 \mathrm{mg} / \mathrm{kg}$ $(+)$-naloxone-treated, and $60 \mathrm{mg} / \mathrm{kg}(+)$-naloxone-treated mice were $73.6 \pm 13.7,80.8 \pm 19.8$, and $58.2 \pm 19.7 \mathrm{mg} / \mathrm{dl}$, respectively. Administration of $60 \mathrm{mg} / \mathrm{kg}(+)$-naloxone over $4 \mathrm{~d}$ also
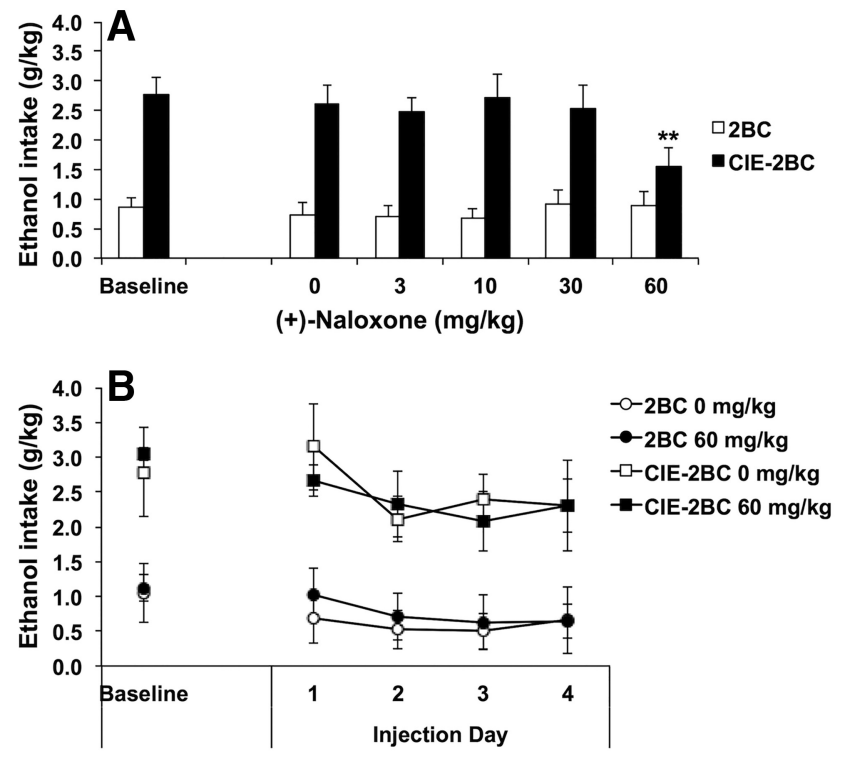

Figure 7. Effect of (+)-naloxone on ethanol intake in the $2 B C$ and $C I E-2 B C$ tests in C57BL/6J mice. $A$, Effect of individual doses of (+)-naloxone on $2 B C$ intake $(\mathrm{g} / \mathrm{kg} / 2 \mathrm{~h})$. Increased ethanol (15\%) consumption was observed in the CIE-2BC group compared with the control $2 \mathrm{BC}$ group $\left(t_{(28)}=5.8, p<0.0001\right)$. Male $(57 \mathrm{BL} / 6 \mathrm{~J}$ mice ( $n=15$ per group) were administered (+)-naloxone $(0,3,10,30,60 \mathrm{mg} / \mathrm{kg})$ in a within-subject manner (every $3-4$ d) 30 min before $2 B C$ testing. The data are presented as mean \pm SEM. Data were analyzed by two-way repeated-measures ANOVA (group as the between factor; dose as the within factor). $\boldsymbol{B}$, Effect of $4 \mathrm{~d}$ of $60 \mathrm{mg} / \mathrm{kg}(+)$-naloxone treatment on $2 \mathrm{BC}$ drinking $(\mathrm{g} / \mathrm{kg} / 2 \mathrm{~h})$. The mice were then divided into two groups to receive (+)-naloxone or vehicle based on equal drinking averages. Male mice in a between-subject design $(n=4-6$ per group: controlvehicle, control-60 mg/kg (+)-naloxone, (IE-vehicle, (IE-60 mg/kg (+)-naloxone) were injected 30 min before $2 B C$ testing across $4 \mathrm{~d}$. The data are presented as mean \pm SEM. Data were analyzed by three-way repeated-measures ANOVA (group and dose as the between factors; day as the within factor). ${ }^{* *} p<0.01$ compared with baseline.

had no significant effect on DID (Fig. 6B) or on BEC. There was a trend toward reduction of drinking by $(+)$-naloxone at $2 \mathrm{~h}$ $\left(F_{(1,14)}=3.1, p=0.1\right)$, but not at $4 \mathrm{~h}\left(F_{(1,14)}=1.5, p=0.2\right)$. BECs measured at $4 \mathrm{~h}$ for vehicle- and $60 \mathrm{mg} / \mathrm{kg}(+)$-naloxone-treated mice were $71.9 \pm 21.2$ and $41.9 \pm 5.6 \mathrm{mg} / \mathrm{dl}$, respectively, but the effect was not significant $\left(F_{(1,14)}=1.9, p=0.2\right)$.

\section{Effect of $(+)$-naloxone on $2 B C$ and CIE-2BC drinking in C57BL/6J mice}

We then tested the effect of individual injections of $(+)$-naloxone (3-60 mg/kg) in mice under conditions of 2BC excessive drinking after CIE exposure. BECs were $186.6 \pm 7.2,149.6 \pm 10.7$, 

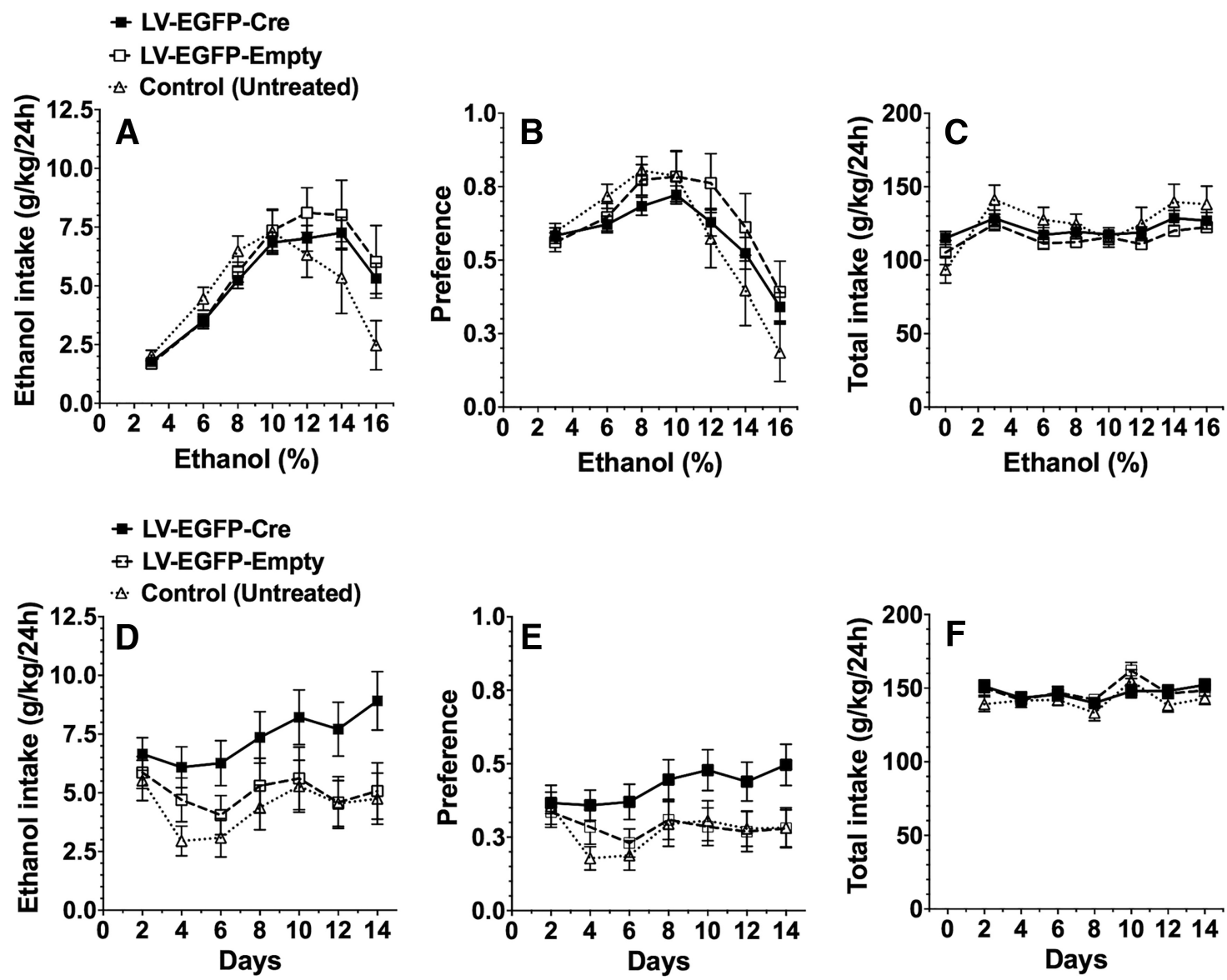

Figure 8. Effect of T/r4 knockdown in NAc on ethanol intake in the continuous and intermittent access $2 B C$ tests in $T / r 4^{\mathrm{F} / \mathrm{F}}$ male mice. $\boldsymbol{A}-\boldsymbol{C}$, Ethanol intake $(\mathrm{g} / \mathrm{kg} / 24 \mathrm{~h})(\boldsymbol{A})$, preference for ethanol $(B)$, and total fluid intake $(\mathrm{g} / \mathrm{kg} / 24 \mathrm{~h})(\boldsymbol{C})$ in the $2 B C$ continuous access test in untreated control T/r $\mathrm{F}^{\mathrm{F} / \mathrm{F}}$ mice $(n=10)$ and $\mathrm{T} / \mathrm{r} \mathrm{F}^{\mathrm{F} / \mathrm{F}}$ mice injected with LV-Cre-EGFP $(n=20)$ or LV-Cre-Empty $(n=10)$. $\boldsymbol{D}-\boldsymbol{F}$, Ethanol (15\%) intake $(\mathrm{g} / \mathrm{kg} / 24 \mathrm{~h})(\boldsymbol{D})$, preference for ethanol $(\boldsymbol{E})$, and total fluid intake $(\mathrm{g} / \mathrm{kg} / 24 \mathrm{~h})(\boldsymbol{F})$ in the $2 \mathrm{BC}$ intermittent access test in untreated control $\mathrm{T} / \mathrm{r} \mathbf{F}^{\mathrm{F} / \mathrm{F}}$ mice $(n=10)$ and $\mathrm{T} / \mathrm{r} \mathbf{4}^{\mathrm{F} / \mathrm{F}}$ mice injected with LV-Cre-EGFP $(n=20)$ or LV-Cre-Empty $(n=11)$. Each point is the average of $2 \mathrm{~d}$ of drinking. The data are presented as mean \pm SEM. Data were analyzed by two-way repeated-measures ANOVA.
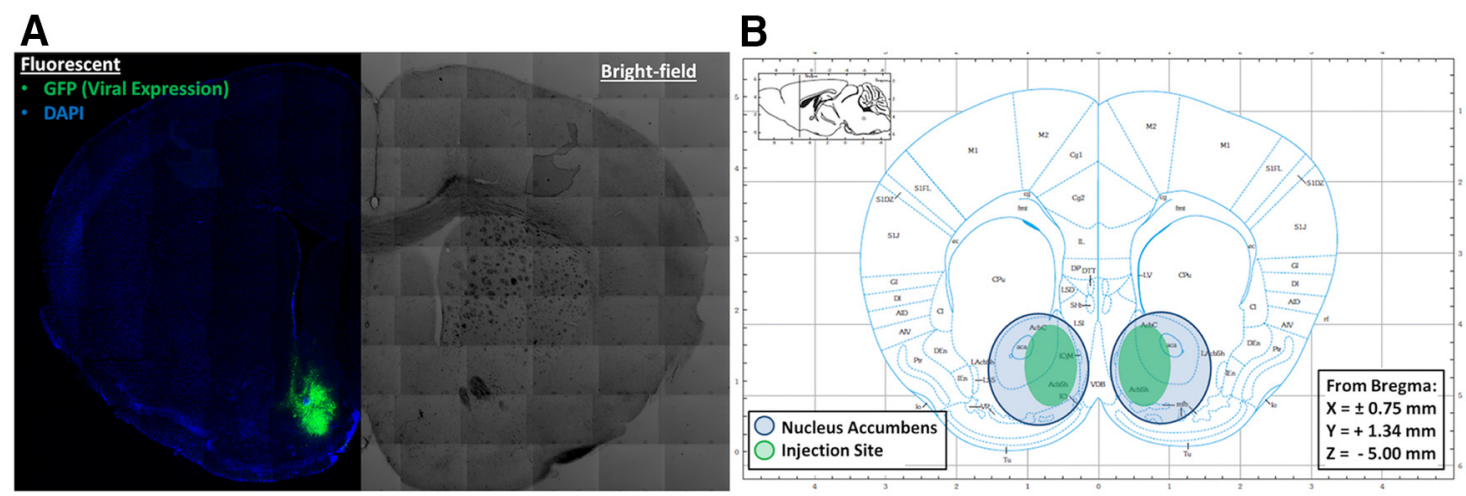

Figure 9. Verification of injection site after T/r4 mRNA knockdown in NAc. A, Composite microscope image of a coronal section of the NAc after lentivirus injection using fluorescent microscopy (left) to show EGFP marker signal (green) and bright-field (right) to demonstrate neuroanatomy. $\boldsymbol{B}$, Coronal brain atlas diagram of the NAc injection site with blue circles showing the NAc and green ovals illustrating the typical lentivirus location and spread.

$174.8 \pm 9.8$, and $176.6 \pm 9.0 \mathrm{mg} / \mathrm{dl}$ across the four cycles of vapor exposure. Increased ethanol (15\%) drinking over $2 \mathrm{~h}$ was observed in the CIE-2BC group compared with the control 2BC group (Fig. 7A). An overall within-subjects ANOVA revealed a significant effect of group $\left(F_{(1,28)}=30.5, p<0.0001\right)$ and a group $\times$ dose interaction $\left(F_{(4,112)}=3.2, p<0.05\right)$. Further analysis revealed that this interaction was due to the decrease in ethanol intake by $60 \mathrm{mg} / \mathrm{kg}(+)$-naloxone compared with vehicle $(p<0.01)$ and compared with $3 \mathrm{mg} / \mathrm{kg}(p<0.05), 10 \mathrm{mg} / \mathrm{kg}$ $(p<0.01)$, and $30 \mathrm{mg} / \mathrm{kg}(p<0.01)(+)$-naloxone in the CIE group. There was no effect of $(+)$-naloxone in the control $2 \mathrm{BC}$ group. To further explore the high dose, we treated separate groups of control $2 \mathrm{BC}$ and CIE-2BC mice with $60 \mathrm{mg} / \mathrm{kg}(+)$ naloxone for $4 \mathrm{~d}$ (Fig. $7 B$ ). There was a significant difference between $2 \mathrm{BC}$ and CIE-2BC mice in baseline drinking $\left(F_{(1,16)}=\right.$ 23.2, $p<0.001)$ after vapor exposure. These groups were each 
divided into two subgroups to receive $(+)$-naloxone or vehicle based on equal drinking averages and equal BECs in the CIE-2BC groups. Vapor chamber BECs for the vehicle-treated mice were $165.7 \pm 12.5,176.6 \pm 3.2,176.6 \pm 16.8$, and $214.9 \pm 20.0 \mathrm{mg} / \mathrm{dl}$ and BECs for the $60 \mathrm{mg} / \mathrm{kg}(+)$-naloxone-treated mice were $170.7 \pm 14.1,187.9 \pm 9.6,191.3 \pm 9.1$, and $214.1 \pm 14.4 \mathrm{mg} / \mathrm{dl}$ across the 4 cycles of exposure. Although the CIE effect was significant $\left(F_{(1,16)}=30.2, p<0.001\right)$, there was no significant treatment effect $\left(F_{(1,16)}=0.0005, p=1.0\right)$ or group $\times$ treatment interaction $\left(F_{(1,16)}=0.2, p=0.6\right)$. Within-dose comparisons across injections also revealed no overall significant effects, but if each treatment day is compared with baseline, there was a significant effect of $60 \mathrm{mg} / \mathrm{kg}(+)$-naloxone on day $3(p=0.03)$. However, drinking did not differ from vehicle-treated mice on this (or any other) day. These results support a modest but inconsistent effect of $60 \mathrm{mg} / \mathrm{kg}(+)$-naloxone on ethanol drinking in dependent mice.

Effect of Tlr4 mRNA knockdown in mouse NAc on $2 B C$ drinking Selective knockdown of TLR4 signaling in the CeA or VTA (but not the VP) decreased binge-like drinking in $\mathrm{P}$ rats (Liu et al., 2011; June et al., 2015). In the current study, we examined Tlr4 knockdown in mouse NAc, another important brain region in binge drinking. However, knockdown in the NAc did not alter ethanol intake, preference for ethanol, or total fluid intake in the $24 \mathrm{~h}$ continuous access $2 \mathrm{BC}$ test in which $\mathrm{Tlr} 4^{\mathrm{F} / \mathrm{F}}$ treated and untreated mice could drink either water or a series of increasing ethanol (3-16\%) concentrations (Fig. 8A-C).

In the $2 \mathrm{BC}$ test with intermittent access to $15 \%$ ethanol, comparison of $T l r 4^{\mathrm{F} / \mathrm{F}}$ treated (LV-EGFP-Cre; LV-EGFP-Empty) and control (untreated) mice revealed a significant treatment $X$ day interaction for ethanol consumption $\left(F_{(6,174)}=2.3 ; p<0.05\right)$, but not for ethanol preference or total fluid intake (Fig. $8 D-F$ ). Twoway repeated-measures ANOVA showed no main effect of treatment in any test. Post hoc analyses for each day when corrected for multiple comparisons also showed no significant differences between LV-EGFP-Cre versus LV-EGFP-Empty treated mice or between LV-EGFP-Cre treated versus control untreated mice. Although there was a trend toward increased alcohol consumption in the intermittent test after Tlr4 mRNA knockdown in NAc, this was not statistically significant.

\section{Verification of Tlr4 knockdown in NAc}

Verification of successful knockdown of Tlr4 mRNA in the NAc involved a two-step process: (1) confirmation of needle placement and (2) quantitation of Tlr4 mRNA. Half of the treated (LV-EGFP-Cre, LV-EGFP-Empty) Tlr4 ${ }^{\mathrm{F} / \mathrm{F}}$ mice were used to verify injection coordinates. Figure $9 A$ is a representative image of a coronal section of the NAc (AP $+1.49 \mathrm{~mm})$ from a lentivirustreated $\mathrm{Tlr} 4^{\mathrm{F} / \mathrm{F}}$ mouse. The left side is a fluorescent image that shows the EGFP signal (surrogate marker for lentivirus transduction) in green and DAPI (a stain that visualizes the nuclei of all cells) in blue. The right side of the image is a bright-field image used to better visualize the neuroanatomical landmarks. Figure $9 B$ is a brain atlas image of a coronal section ( $\mathrm{AP}+1.49 \mathrm{~mm})$ showing the desired target coordinates, with the blue circles highlighting the NAc and the green ovals demonstrating the location of the LV-EGFP-Cre and LV-EGFP-Empty infection. All samples obtained from mice in both drinking experiments were on target and demonstrated an EGFP signal that covered at least one-third of the NAc.

Micropunches of the injection site were obtained from the other half of the treated (LV-EGFP-Cre, LV-EGFP-Empty)

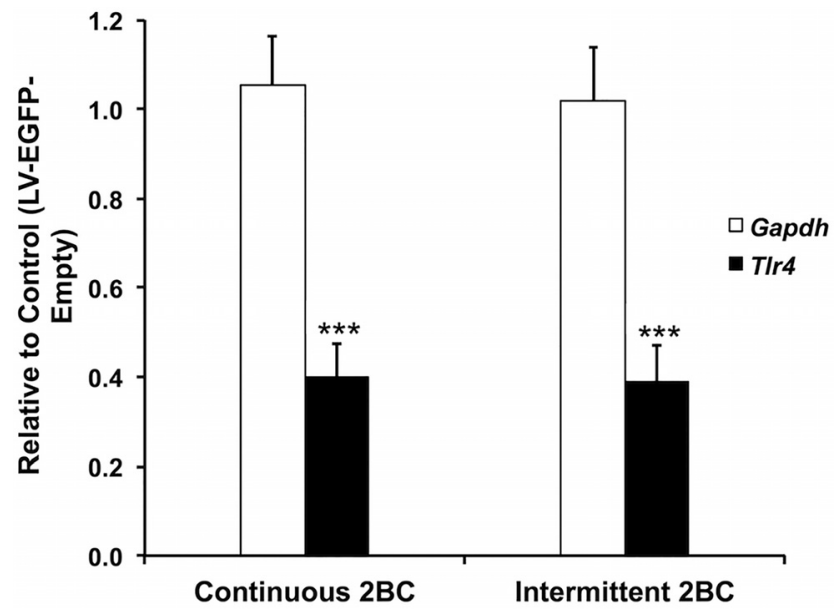

Figure 10. Verification of TIr4 mRNA knockdown after lentivirus injections in NAc. TIr4 mRNA levels in the NAc target site were assessed by qPCR and normalized relative to Gadph mRNA levels after the 2BC continuous access ( $n=12$, LV-EGFP-Cre; $n=7$, LV-EGFP-Empty) and 2BC intermittent access tests ( $n=11$, LV-EGFP-Cre; $n=7$, LV-EGFP-Empty). Values (mean \pm SEM) are shown relative to LV-EGFP-Empty treated mice; ${ }^{* * *} p<0.001$ determined by Student's $t$ test.

$T l r 4^{\mathrm{F} / \mathrm{F}}$ mice. The extracted RNA had excellent yields, purity, and quality; RNA integrity numbers averaged $>8.0$, indicating little or no degradation, and the $260 / 230$ and $260 / 280$ ratios were $>2.0$. We observed $>60 \%$ knockdown $(p<0.001)$ of Tlr4 mRNA relative to the endogenous control 8 weeks after injection in mice exposed to $2 \mathrm{BC}$ continuous and intermittent access drinking tests (Fig. 10).

\section{Role of TLR4 in the acute behavioral actions of ethanol}

Reduced duration of ethanol-induced LORR in Tlr4 KO rats Previous work in mice showed that lack of Tlr4 or administration of $(+)$-naloxone reduced the duration of LORR induced by a single high dose of ethanol ( $4.5 \mathrm{~g} / \mathrm{kg}$ ) (Corrigan et al., 2015). We tested a single high dose of ethanol $(4.0 \mathrm{~g} / \mathrm{kg})$ in rats and also found that the latency to induction of ethanol-induced LORR was significantly increased (Fig. 11A) and the duration of LORR was significantly reduced (Fig. 11B) in Tlr4 KO rats compared with WT rats.

\section{Role of TLR4 in GABAergic transmission in CeA neurons} Spontaneous GABAergic transmission

We examined GABAergic transmission in CeA neurons from Tlr4 KO and WT rats based on the evidence for TLR4 pathway signaling in GABAergic synapses in mouse CeA (Bajo et al., 2014). The effect of an acute application of ethanol ( $44 \mathrm{~mm})$ on GABAergic transmission was tested in CeA neurons of naive WT and Tlr $4 \mathrm{KO}$ rats and after CIE or a single LPS challenge (experiments performed 7-10 d after LPS injection). We found no significant differences in the baseline s/mIPSC frequencies, amplitudes, or decay times in CeA neurons from WT and Tlr4 KO mice (Table 1). However, we observed a significant $(p<$ 0.05 ) difference in baseline MIPSC rise times between the genotypes (Table 1). In addition, whereas LPS and CIE treatments had no effect on s/mIPSC parameters across genotypes, both treatments significantly $(p<0.05)$ altered s/mIPSC rise times in WT and Tlr4 KO mice (Table 1).

\section{Acute ethanol application}

We also compared the effects of acute ethanol application on GABAergic transmission in CeA neurons from naive WT and 


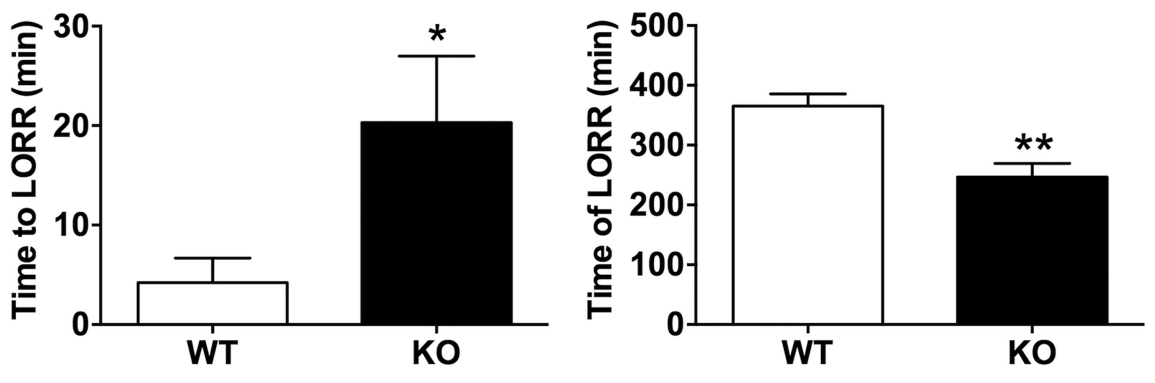

Figure 11. The sedative effects of ethanol are reduced in T/r4 KO male rats. Left panel, Time to LORR in male WT and T/r4 KO rats ( $n=10$ per group, $\mathrm{df}=18, t=2.3, p<0.05$ ). Right panel, Time of LORR in WT and TIr4 KO rats ( $n=10$ per group, $\mathrm{df}=18, t=$ $3.9, p<0.01$ ). The data are presented as mean \pm SEM in minutes. ${ }^{*} p<0.05$ and ${ }^{* *} p<0.01$ determined by unpaired Student's $t$ test.

Tlr4 KO rats. Ethanol $(44 \mathrm{~mm})$ significantly $(p<0.01-0.05)$ increased s/mIPSC frequencies in CeA neurons from both genotypes; ethanol increased the mean sIPSC frequency by $37.6 \pm$ $11.4 \%$ in WT and $45.7 \pm 14.2 \%$ in Tlr4 KO rats (Fig. $12 A, B$ ) and increased the mIPSC frequency by $26.4 \pm 7.1 \%$ in WT and $43.6 \pm$ $13.5 \%$ in Tlr4 KO rats (Fig. 13C,D). Acute ethanol did not alter s/mIPSC amplitudes or kinetics in CeA neurons from either genotype (Fig. 12). There was no significant difference in the acute ethanol-induced increases of CeA GABA release in neurons from naive WT and Tlr4 $\mathrm{KO}$ rats.

\section{CIE vapor exposure}

In CeA neurons from CIE-treated WT and Tlr4 $\mathrm{KO}$ rats, acute ethanol (44 mM) application also increased s/mIPSC frequencies (Fig. 13). Two-way repeated-measures ANOVA of the peak ethanol effects from all of the tested cells showed a significant main effect of ethanol $\left(F_{(1,16)}=9.3, p<0.05\right)$, but no effect of genotype or interaction between ethanol and genotype. Ethanol significantly facilitated sIPSC frequencies in WT neurons by $57.2 \pm$ $4.3 \%$, but had mixed effects in the CeA neurons from Tlr4 KO rats. For example, ethanol enhanced sIPSC frequencies in only 6 of 10 Tlr $4 \mathrm{KO}$ neurons (47\% of control) and either decreased $(<$ $85 \%$ of control, $n=3$ ) or had no effect $(85-115 \%$ of control, $n=$ 1 ) in the remaining neurons. Although the magnitude of the acute ethanol effect on s/mIPSC frequencies was similar in CIEtreated and naive WT and Tlr4 $\mathrm{KO}$ rats, the ethanol-induced facilitation of sIPSC frequency was transient (5-6 min) in the CIE-treated Tlr4 $\mathrm{KO}$ rats compared with the other 3 groups (12-15 min; data not shown). Consistent, sustained ethanolinduced increases in mIPSC frequencies were observed in both WT and Tlr4 KO neurons. Two-way repeated-measures ANOVA showed a significant main effect of ethanol $\left(F_{(1,9)}=19.8, p<\right.$
0.05), but not genotype or the interaction between ethanol and genotype. There were no significant acute ethanol-induced changes in the amplitude and kinetics of s/mIPSCs in CIE-treated WT and Tlr4 KO rats.

\section{LPS exposure}

We investigated the effects of acute ethanol application on CeA neurons from WT and Tlr $4 \mathrm{KO}$ rats $7-10 \mathrm{~d}$ after a single LPS injection $(1 \mathrm{mg} / \mathrm{kg}$, i.p.). There was a significant main effect of ethanol treatment $\left(F_{(1,13)}=5.9, p<0.05\right)$, but not genotype, and no significant interaction between genotype and ethanol. Ethanol (44 mM) had opposite effects on sIPSC frequency in WT versus Tlr4 KO rats, represented by a significant reduction of $41.4 \pm 4.0 \%$ in the LPS-treated WT neurons (Fig. 14). Although there was an overall significant increase of $29.9 \pm 21.6 \%$ in sIPSC frequency by acute ethanol in neurons from LPS-treated Tlr4 KO rats (Fig. 14), ethanol produced mixed, cell-specific effects; ethanol increased the frequencies in 3 of 7 cells ( $>115 \%$ of control, $n=3$ ), but had no effect $(85-115 \%$ of control, $n=4)$ in the others. There were no significant ethanol-induced changes in the sIPSC amplitude and kinetics between the two groups.

Finally, we compared the normalized effects of acute ethanol on s/mIPSC frequencies across the different treatment groups using two-way ANOVA. There was a significant main effect of treatment $\left(F_{(2,46)}=6.7, p<0.01\right)$, but not genotype $\left(F_{(2,46)}=\right.$ $1.3, p>0.05)$, on sIPSC frequencies and a significant interaction between treatment and genotype $\left(F_{(2,46)}=7.3, p<0.01\right)$. Bonferroni post hoc tests showed significant differences in ethanol effects in the LPS-treated rats compared with naive and CIEtreated WT rats, whereas there were no significant differences among the individual treatment groups of Tlr4 $\mathrm{KO}$ rats. There were no main effects of treatment or genotype on acute ethanolinduced potentiation of MIPSC frequencies between naive and CIE-treated rats.

\section{Discussion}

INIA-Neuroimmune investigators used extensive behavioral and electrophysiological tests to examine the role of TLR4 in acute and chronic ethanol responses in rats and mice (summarized in Table 2). Different genetic and pharmacologic approaches were used to inhibit TLR4-mediated signaling and different

Table 1. Baseline spontaneous and miniature IPSCs in CeA neurons from naive, CIE-treated, and LPS-treated WT and TIr 4 KO rats

\begin{tabular}{|c|c|c|c|c|c|c|c|c|}
\hline \multirow[b]{2}{*}{ Group } & \multicolumn{4}{|c|}{ Spontaneous IPSCs } & \multicolumn{4}{|c|}{ Miniature IPSCs } \\
\hline & Frequency & Amplitude & Rise time $^{* *}$ & Decay time & Frequency & Amplitude & Rise time ${ }^{*} \# \#$ & Decay time \\
\hline WT Naive & $1.1 \pm 0.4$ & $79.6 \pm 6.1$ & $2.8 \pm 0.1$ & $8.7 \pm 0.9$ & $0.5 \pm 0.1$ & $52.7 \pm 2.2$ & $3.1 \pm 0.2$ & $7.1 \pm 1.9$ \\
\hline KO Naive & $1.1 \pm 0.4$ & $78.9 \pm 11.3$ & $3.1 \pm 0.2$ & $9.1 \pm 0.9$ & $0.3 \pm 0.1$ & $56.8 \pm 3.7$ & $2.5 \pm 0.1$ & $5.6 \pm 0.4$ \\
\hline WT CIE & $1.0 \pm 0.4$ & $65.2 \pm 6.1$ & $2.7 \pm 0.1$ & $8.5 \pm 0.7$ & $0.3 \pm 0.1$ & $46.6 \pm 6.7$ & $2.7 \pm 0.2$ & $5.6 \pm 0.8$ \\
\hline KO CIE & $1.0 \pm 0.4$ & $80.2 \pm 13.6$ & $2.4 \pm 0.2$ & $8.7 \pm 1.1$ & $0.4 \pm 0.1$ & $58.8 \pm 5.4$ & $2.2 \pm 0.1$ & $6.1 \pm 0.5$ \\
\hline WT LPS & $1.3 \pm 0.3$ & $98.9 \pm 19.1$ & $2.5 \pm 0.1$ & $10.6 \pm 0.8$ & N/A & N/A & $\mathrm{N} / \mathrm{A}$ & $\mathrm{N} / \mathrm{A}$ \\
\hline KO LPS & $1.5 \pm 0.6$ & $70.7 \pm 5.7$ & $2.4 \pm 0.1$ & $8.6 \pm 1.7$ & N/A & N/A & N/A & N/A \\
\hline
\end{tabular}

IPSCs in CeA neurons from naive rats (WT: $n=13 ; \mathrm{KO}: n=12$ ), CIE-exposed rats (WT: $n=8 ; \mathrm{KO}: n=10$ ), and ethanol-naive rats (WT: $n=8 ; \mathrm{K} 0: n=8)$ injected with LPS (1 mg/kg, i.p.). Two-way ANOVA revealed no main effects of treatment, genotype, or the interaction of baseline frequencies, amplitudes, and decay times of the spontaneous IPS(s. There was a main effect of treatment $\left(F_{(2.53)}=7.7 ; p<0.01\right)$ on the rise time, but no main effect of genotype or interaction between genotype and treatment. Likewise, there were no main effects of treatment or genotype and no interaction between treatment and genotype on the frequency, amplitude, and decay time of baseline miniature IPSCS from naive (WT: $n=5 ; \mathrm{KO}: n=9$ ) and CIE-exposed (WT: $n=5 ; \mathrm{KO}: n=6)$ rats. However, there were significant main effects of treatment $\left(F_{(1,21)}=7.4, p<0.05\right)$ and genotype $\left(F_{(1,21)}=13.8, p<0.01\right)$ on baseline miniature IPSC rise time, but no interaction between genotype and treatment. Values are mean \pm SEM.

${ }^{*} p<0.05,{ }^{* *} p<0.01$, effect of treatment; \#\#p $<0.01$, effect of genotype.

$\mathrm{N} / \mathrm{A}$, Not applicable. 
A

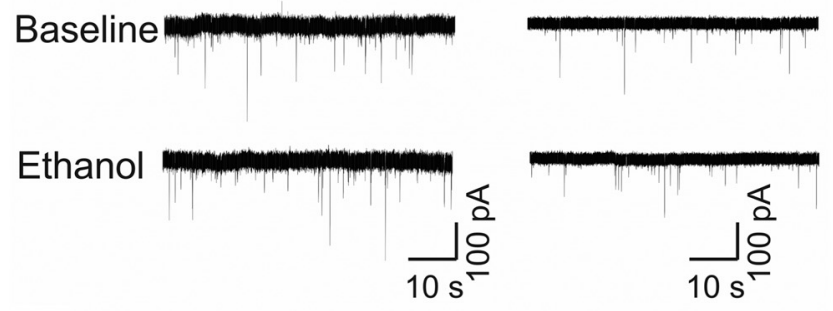

B

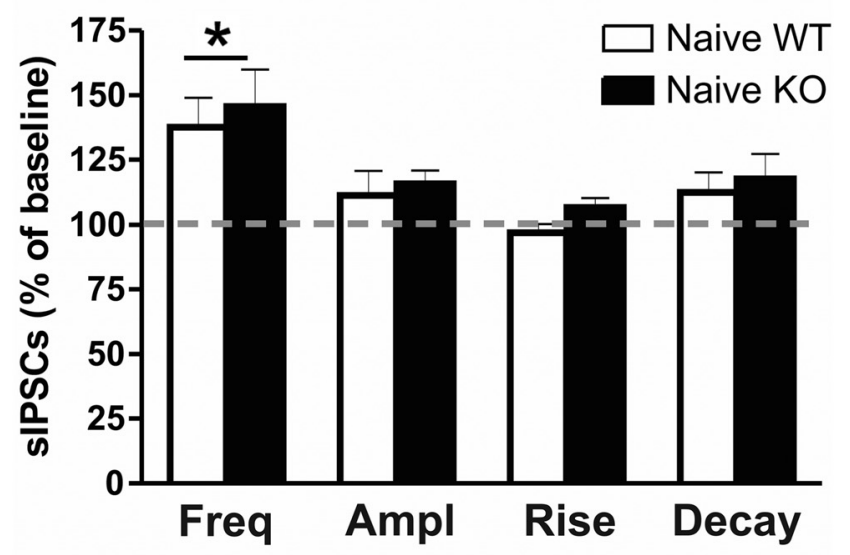

C
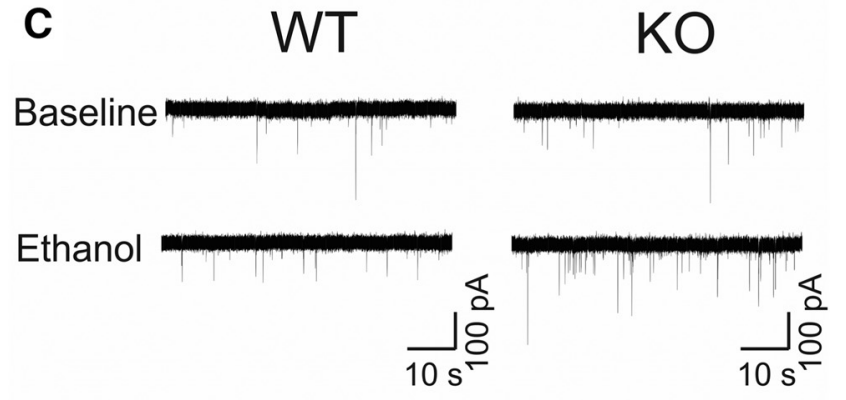

D

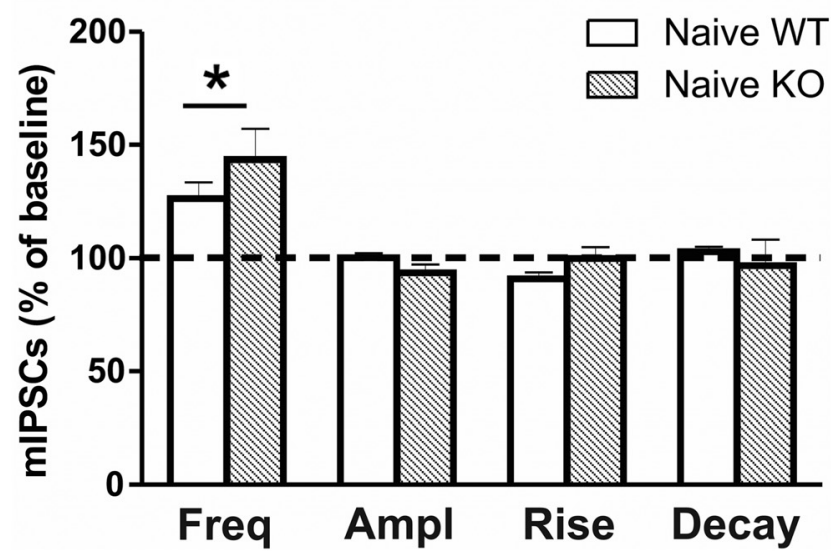

Figure 12. Acute ethanol potentiates spontaneous and miniature GABA release in CeA neurons from ethanol-naive WT and TIr4 KO rats. $A$, Traces of representative sIPSC recordings of CeA neurons from naive WT (left) and TIr4 KO (right) male rats before and after acute bath application of ethanol ( $44 \mathrm{~mm}$ ). $\boldsymbol{B}$, Acute ethanol increased the mean sIPSC frequency in CeA neurons by $37.6 \pm 11.4 \%$ in WT (from $1.4 \pm 0.5$ to $1.6 \pm 0.6 \mathrm{~Hz}, n=9$ ) and by $45.7 \pm 14.2 \%$ in K0 (from $0.9 \pm 0.2$ to $1.2 \pm 0.3 \mathrm{~Hz}, n=10$ ) rats. There was a significant main effect of ethanol $\left.\left(F_{(1,17)}\right)=11.0, p<0.01\right)$, but no main effect of genotype or interaction between ethanol models of voluntary ethanol intake were studied in male and female rodents.

In addition to genotyping, rats were injected with LPS to verify that TLR4, a primary target, was nonfunctional in the KO animals. LPS produced "sickness-like" behavior in naive and ethanol-treated WT rats, represented by decreased food/water intake and body weight; however, Tlr4 KO rats were resistant to these effects as reported previously in Tlr4 KO mice (Qureshi et al., 1999; Kalis et al., 2003; von Meyenburg et al., 2004; Yang et al., 2014). We further demonstrated that WT ethanol-trained rats developed tolerance to LPS-induced toxicity in agreement with studies in ethanol-naive rats (McCarthy et al., 1984; Cross-Mellor et al., 2000). Female B6 mice also showed evidence of tolerance to decreased body weight after a second LPS injection (Blednov et al., 2011).

LPS increased ethanol consumption in mice (Blednov et al., 2011) and elevated serum levels of LPS were positively correlated with alcohol craving in humans (Leclercq et al., 2012; Leclercq et al., 2014). In WT rats, LPS transiently reduced ethanol self-administration, but had no long-term effects on drinking in either genotype. The initial reduction in ethanol responding (1-4 d after LPS) may be due to induction of "sickness-like" behavior that affects the motivation for ethanol similar to effects on food/water intake. We found no differences in ethanol self-administration in WT and Tlr4 KO rats before or after dependence and no consistent genotype differences in 2BC drinking over 5 weeks. The inconsistent decrease in dependence-driven drinking by $60 \mathrm{mg} / \mathrm{kg}(+)$-naloxone may be due to nonspecific/aversive effects of this high dose, as reported in rats (Tanda et al., 2016).

TLR4 knockdown in the CeA or VTA decreased binge drinking in P rats (Liu et al., 2011; June et al., 2015). Given the prominent role of the NAc within the mesocorticolimbic reward circuit in alcohol abuse and dependence, we further studied the effects of TLR 4 in this brain region. However, Tlr4 mRNA knockdown in mouse NAc did not reduce $2 \mathrm{BC}$ continuous or limited access drinking. In addition to brain region, there are other key differences between the studies. We examined male C57BL/6J mice using the $2 \mathrm{BC}$ continuous and intermittent models, whereas the previous work was in $\mathrm{P}$ rats (the sex was not reported) using a binge-drinking model. The $\mathrm{P}$ rats had increased levels of $\mathrm{GABA}_{\mathrm{A}}$ receptor $\alpha 2$ subunits and TLR 4 in the CeA and VTA, and $\alpha 2$ subunit-specific knockdown in the CeA inhibited TLR4 function and decreased drinking (Liu et al., 2011). Furthermore, Tlr4 knockdown in the CeA decreased $\alpha 2$ subunit expression and also reduced drinking (Liu et al., 2011). Therefore, the TLR4-related effects on binge drinking in $\mathrm{P}$ rats may be due to altered GABAergic ( $\alpha 2$ subunit-specific) responses.

Although TLR4 signaling did not regulate ethanol consumption consistently in our rodent models or in other studies

and genotype. Acute ethanol did not have significant effects on sIPSC amplitudes (WT:111.3 \pm 9.4\% of control; K0: $115.8 \pm 5.1 \%$ of control) or kinetics (rise time: WT, $97.0 \pm 3.3 \%$ of control; K0, $106.6 \pm 3.7 \%$ of control; decay time: WT, $112.5 \pm 7.5 \%$ of control; K0, $117.6 \pm 9.7$ of control). C, Representative mIPSCs recorded from CeA neurons of naive WT and TIr4 KO rats showing an increase in mIPSC frequencies after acute ethanol application. $\boldsymbol{D}$, Acute ethanol increased mIPSC frequencies in CeA WT and T/r $4 \mathrm{KO}$ neurons. There was a significant main effect of ethanol $\left(F_{(1,12)}=11.8, p<0.05\right)$ on mIPSC frequencies in WT $(26.4 \pm 7.1 \%$; from $0.5 \pm 0.1$ to $0.6 \pm 0.1 \mathrm{~Hz}, n=5)$ and $\mathrm{K} 0$ neurons $(43.6 \pm 13.5 \%$; from $0.3 \pm 0.1$ to $0.4 \pm 0.1 \mathrm{~Hz}, n=$ 9), but no significant main effects of genotype or the interaction between ethanol and genotype. Ethanol had no effects on mIPSC amplitudes (WT: $100.3 \pm 2.0 \%$ of control; K0: $93.6 \pm$ $3.6 \%$ of control) or kinetics (rise time: WT, $90.9 \pm 2.8 \%$ of control; $\mathrm{KO}, 99.9 \pm 4.9 \%$ of control; decay time: WT, $102.9 \pm 2.3 \%$ of control; K0, $96.7 \pm 11.6 \%$ of control) in neurons from WT and TIr4 KO rats. Statistical significance was calculated by two-way repeated-measures ANOVA $(\# p<0.05)$. The data are presented as mean \pm SEM. 
A

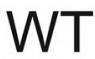

KO

Baseline
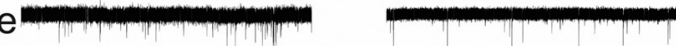

Ethanol
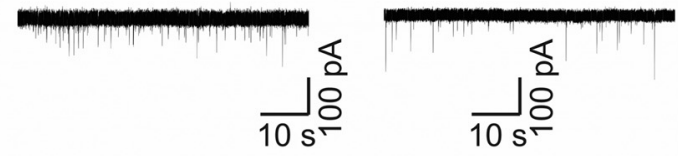

B

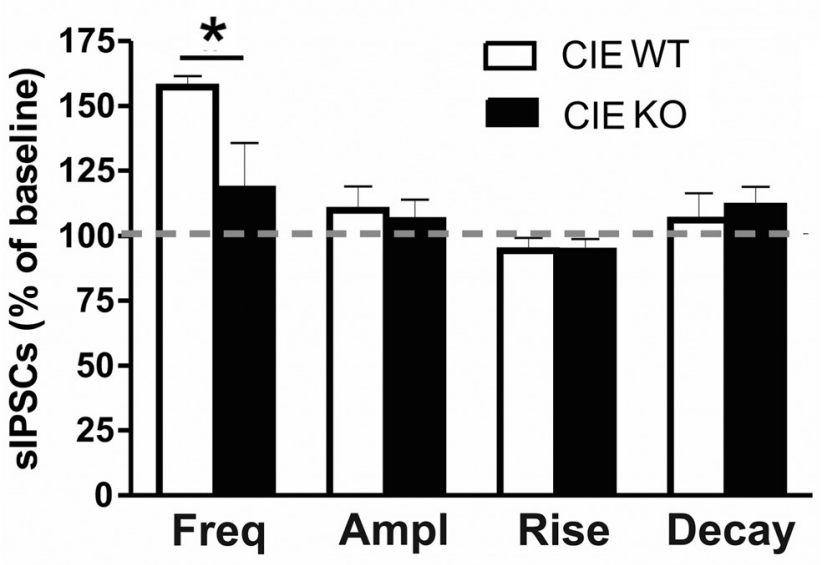

C

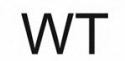

$\mathrm{KO}$

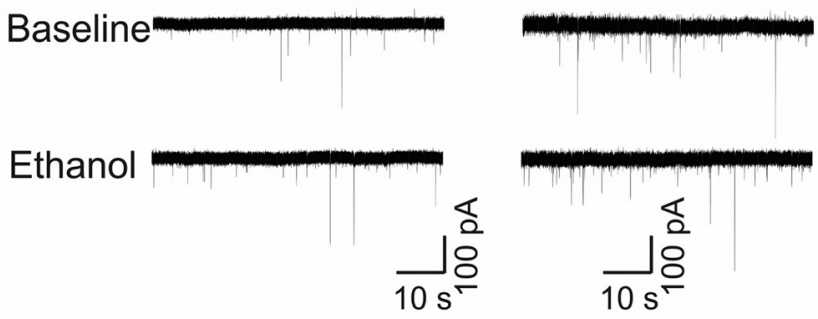

D

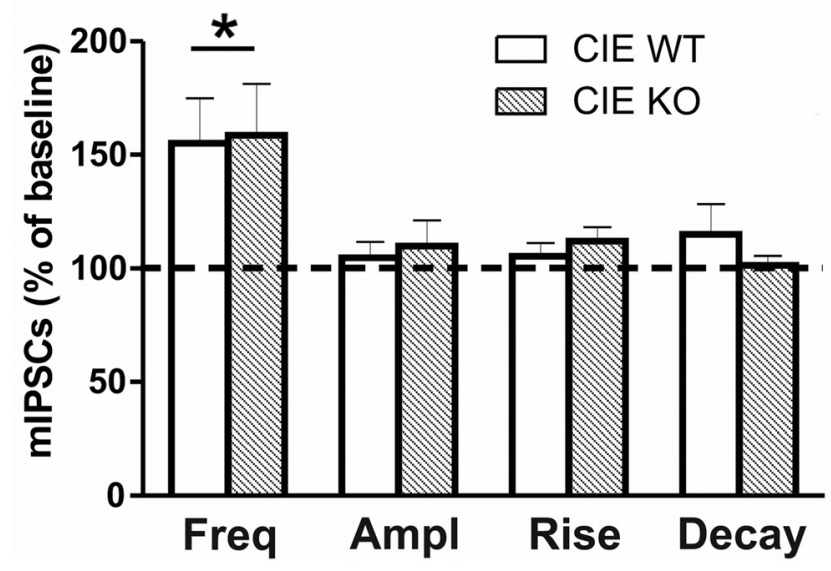

Figure 13. Acute ethanol enhances GABA release in CeA neurons from WT and T/r4 KO rats differentially after CIE exposure. $A$, Traces of sIPSC recordings in CeA neurons from WT and T/r4 KO male rats exposed to CIE vapor. $\boldsymbol{B}$, Bath application of $44 \mathrm{~mm}$ ethanol facilitated sIPSC frequencies in WT neurons significantly by $57.2 \pm 4.3 \%$ (from $1.0 \pm 0.4$ to $1.5 \pm 0.6 \mathrm{~Hz}, n=$ 8 ), but enhanced frequencies in only 6 of $10 \mathrm{KO}$ neurons ( $46.5 \pm 23.1 \%$ of control; from $1.2 \pm$ 0.7 to $1.7 \pm 0.8 \mathrm{~Hz}, n=6$ ) and decreased ( $<85 \%$ of control, $n=3$ ) or had no effect $(85-115 \%$ of control, $n=1)$ on sIPSC frequencies in the remainder $(85.5 \pm 9.3 \%$ of control;
A $\quad$ WT $\quad$ KO

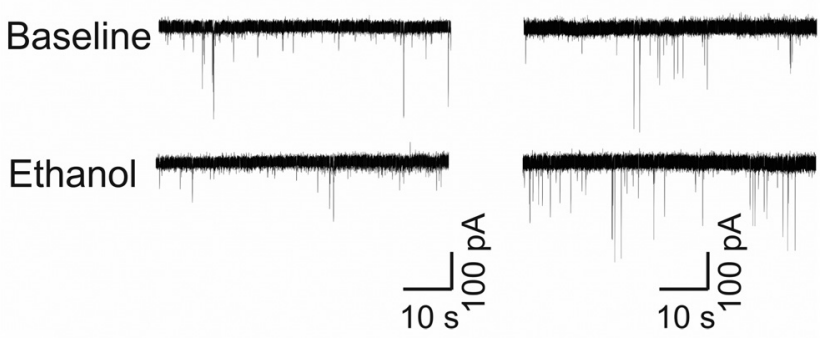

B

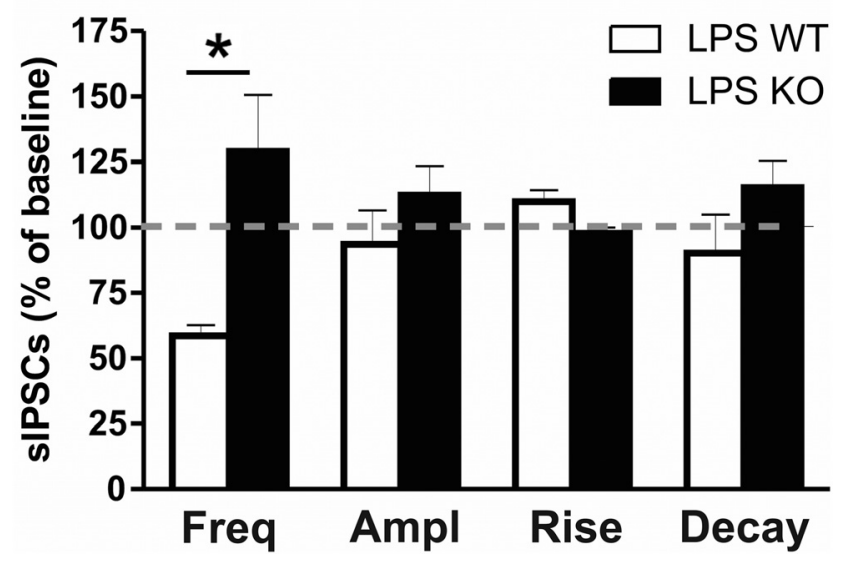

Figure 14. LPS injection alters GABA responses to acute ethanol in CeA neurons from WT but not TIr4 KO rats. $A$, Representative recordings of sIPSCs from LPS-treated WT and TIr4 KO male rats. $\boldsymbol{B}$, Seven to $10 \mathrm{~d}$ after a single LPS injection ( $1 \mathrm{mg} / \mathrm{kg}$, i.p.), acute $44 \mathrm{~mm}$ ethanol application reduced sIPSC frequencies by $41.4 \pm 4.0 \%$ (from $1.3 \pm 0.3$ to $0.7 \pm 0.2 \mathrm{~Hz}, n=8$ ) in CeA neurons from LPS-treated WT rats. Ethanol's effects on sIPSC frequencies in LPS-treated KO rats (an overall increase of $29.9 \pm 21.6 \%, n=7$ ) were more varied, with ethanol-induced potentiation ( $>115 \%$ of control, $n=3$ ) or no effect ( $85-115 \%$ of control, $n=4$ ) occurring in a cell-specific manner. There was a significant main effect of ethanol treatment $\left(F_{(1,13)}=5.9\right.$, $p<0.05$ ), but not genotype, and no interaction between genotype and ethanol. There were no significant effects of acute ethanol on the amplitudes (WT: $93.6 \pm 12.9 \% ; \mathrm{KO}: 112.3 \pm 11.1 \%$ of control) or kinetics (rise time: WT, $109.9 \pm 4.4 \% ; \mathrm{KO}, 97.8 \pm 2.2 \%$; decay time: WT, $90.2 \pm$ $14.7 \%$; K0, $115.2 \pm 10.1 \%$ of control) in LPS-treated WT and T/r4 KO rats. The data are presented as mean \pm SEM. Statistical significance was calculated by two-way repeated-measures ANOVA (\#p $<0.05)$.

(Alfonso-Loeches et al., 2010; Pascual et al., 2011; Bajo et al., 2016; Blednov et al., 2017a), Tlr4 KO rats displayed lower sensitivity than WT to the acute sedative effects of ethanol. This is consistent with results in mice lacking Tlr4 or WT mice treated with (+)-naloxone (Wu et al., 2012b; Corrigan et al., 2015; Bled-

from $0.7 \pm 0.1$ to $0.5 \pm 0.04 \mathrm{~Hz}$ ) of $\mathrm{KO}$ neurons. Two-way repeated-measures ANOVA of the peak ethanol effects from all of the tested cells showed a significant main effect of ethanol $\left(F_{(1,16)}=9.3, p<0.05\right)$, but no effect of genotype or interaction between ethanol and genotype. The acute ethanol effects on SIPSC frequencies were transient in the neurons from KO compared with WT rats. C, Representative mIPSCs in CeA neurons from WT and TIr4 KO rats chronically exposed to ethanol. $\boldsymbol{D}$, Acute ethanol $(44 \mathrm{~mm})$ application increased $\mathrm{mIPSC}$ frequencies in WT and T/r $4 \mathrm{~K} 0$ neurons by $55.1 \pm 19.9 \%$ (from $0.3 \pm 0.1$ to $0.4 \pm 0.1 \mathrm{~Hz}, n=5$ ) and $58.6 \pm 22.6 \%$ (from $0.4 \pm 0.1$ to $0.5 \pm 0.8 \mathrm{~Hz}, n=6$ ), respectively. Two-way repeatedmeasures ANOVA showed a significant main effect of ethanol $\left(F_{(1.9)}=19.8, p<0.05\right)$, but not genotype or the interaction between ethanol and genotype. Acute ethanol had no significant effects on the mean mIPSC amplitudes (WT: 104.8 $\pm 6.9 \%$ of control; KO: $109.9 \pm 11.3 \%$ of control) or kinetics (rise time: WT, $105.4 \pm 5.8 \%$ of control; $\mathrm{KO}, 112.0 \pm 6.2 \%$ of control; decay time: WT, $115.1 \pm 13.3 \%$ of control; KO, $101.4 \pm 4.3 \%$ of control) in WT and T/r $4 \mathrm{KO}$ rats. The data are presented as mean \pm SEM $(\# p<0.05)$. 
Table 2. Summary of tests performed in rats and mice

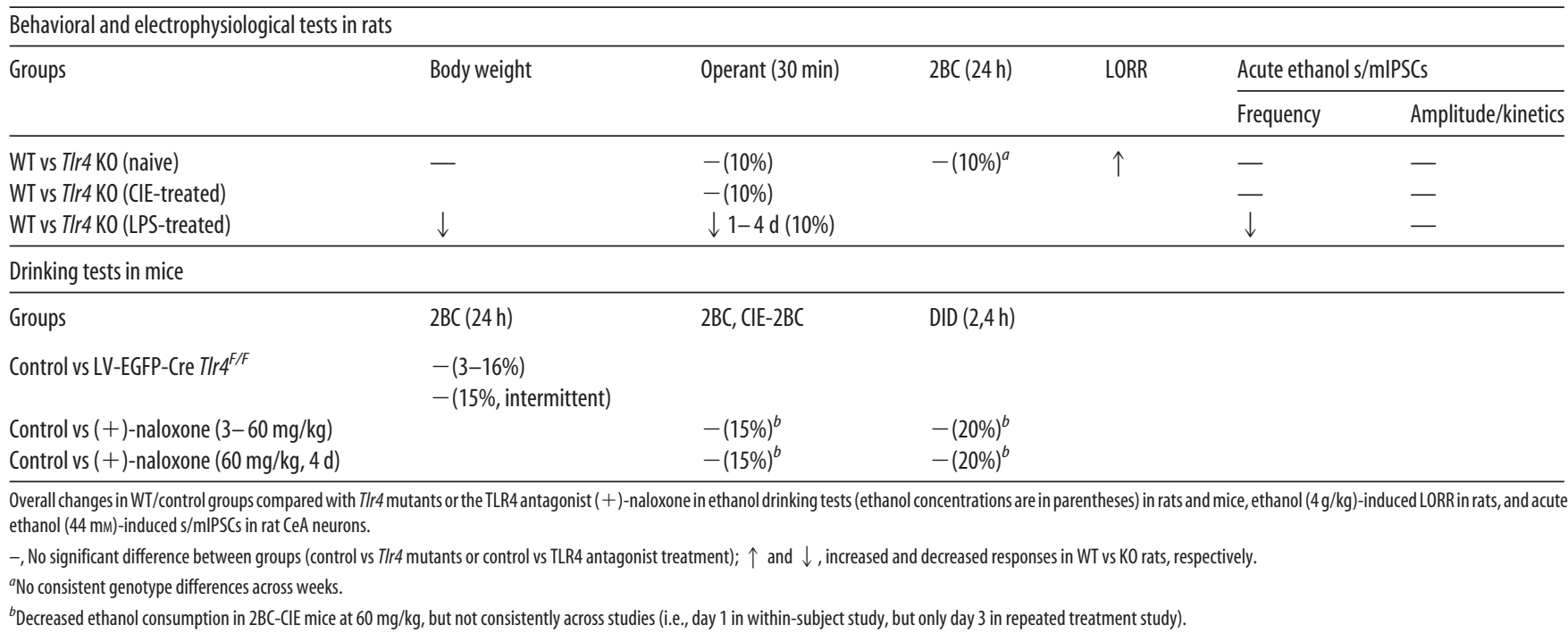

nov et al., 2017b). A complex interaction between TLR2 and TLR4 in ethanol-induced LORR was reported (Corrigan et al., 2015) and ethanol also promoted physical TLR2/TLR4 interactions in lipid rafts, which may facilitate immune activation (Fernandez-Lizarbe et al., 2013). Therefore, a role for TLR signaling in ethanol-induced sedation is emerging across species and TLRs and associated pathways may regulate some of ethanol's acute responses synergistically.

We examined GABAergic transmission in CeA neurons because TLR4 pathway components were involved in ethanol's acute effects on GABAergic IPSPs in these synapses (Bajo et al., 2014) and because Tlr4 knockdown in the CeA of P rats potentially reduced drinking via a GABAergic mechanism (Liu et al., 2011). Deletion of Tlr4 did not affect baseline spontaneous GABA release in $\mathrm{CeA}$ neurons, but altered the kinetics of $\mathrm{GABA}_{\mathrm{A}}$ receptor-mediated IPSCs, indicating a role for TLR4 in $\mathrm{GABA}_{\mathrm{A}}$ receptor function (Otis et al., 1994). Generally, the kinetic properties of $\mathrm{GABA}_{\mathrm{A}}$-mediated currents are determined by subunit composition, posttranslational modifications, trafficking, synaptic localization, and clustering (Jacob et al., 2008; Wu et al., 2012a; Dixon et al., 2014) and we cannot exclude potential contributions from these factors.

Deletion of CD14, an accessory protein for LPS-mediated activation of TLR4, had no effects on CeA GABAergic transmission (Bajo et al., 2014), indicating different synaptic effects for different TLR4 pathway components. However, frequencies of sIPSCs and tonic currents were altered in Illrn KO mice (Bajo et al., 2015). Collectively, our findings support distinct roles for neuroimmune regulators in basal GABAergic transmission.

Acute ethanol increased action potential-dependent and -independent GABA release in CeA neurons from naive and CIEtreated WT and Tlr4 KO rats in agreement with previous studies (Roberto et al., 2003; Roberto et al., 2004; Gilpin et al., 2011; Cruz et al., 2013; Herman et al., 2013). The lack of differences in acute ethanol effects on spontaneous GABAergic transmission, especially in naive rats, agrees with our study suggesting that CD14 (rather than TLR4) is critical for ethanol effects in CeA neurons (Bajo et al., 2014). After LPS exposure, acute ethanol reduced CeA GABAergic transmission in WT but not Tlr4 KO neurons. Previous work in mice showed that LPS reduced firing of VTA neurons and increased ethanol drinking (Blednov et al., 2011). Despite the synaptic changes in WT neurons observed 7-10 d after LPS exposure, LPS did not alter ethanol self-administration in WT or Tlr4 KO rats at this time point. Although our results support the involvement of the TLR4 pathway in regulating CeA GABA transmission, it is likely that other immune mediators released during LPS-induced peripheral and central immune activation contribute to the altered ethanol effects in WT synapses.

In Tlr $4 \mathrm{KO}$ rats after CIE or LPS treatment, we observed cellspecific responses to acute ethanol similar to the variable ethanol effects in naive Cd14 or Il1rn KO mice (Bajo et al., 2014; Bajo et al., 2015). Activation of peripheral immune responses is known to stimulate discrete CeA neurons (Day et al., 1999; Serrats et al., 2006). Overall, these findings point to distinct neuronal populations and circuits in the CeA whose basal activities or ethanol responses are regulated differentially by proinflammatory/neuroimmune molecules.

We used different methods to target TLR4 and different models of ethanol intake, but there was little evidence that TLR4 regulates drinking directly. In microglia, $(+)$-naloxone and $(+)$ naltrexone may block TLR4 downstream signaling preferentially via the TRIF-IRF3 pathway (Wang et al., 2016), indicating that they may not block all arms of TLR4 signaling. Given that there were no consistent differences in 2BC drinking and operant selfadministration of ethanol between WT and Tlr4 KO rats, it is unlikely that the lack of (DID and 2BC) or inconsistent (CIE2BC) effect of (+)-naloxone is due to incomplete TLR4 inhibition, particularly at the $60 \mathrm{mg} / \mathrm{kg}$ dose. Collectively, our results in mice and rats are in agreement with studies showing that Tlr4 KO and WT mice did not differ in ethanol consumption (AlfonsoLoeches et al., 2010; Pascual et al., 2011; Blednov et al., 2017a). Our $(+)$-naloxone results in mice are consistent with another TLR4 inhibitor that also decreased ethanol consumption nonspecifically in mice (Bajo et al., 2016). To date, only knockdown of Tlr4 mRNA in the CeA or VTA of P rats decreased binge drinking and this was associated with $\alpha 2$ subunit-specific GABAergic signaling. However, there is now consistent evidence across species for a role of TLR4 in mediating the acute sedative effects of alcohol, which could be an indicator of overall sensitivity to alcohol and susceptibility to develop dependence.

TLR4 mediates ethanol-induced increases in brain cytokines/ chemokines and neurodegeneration and inhibition of TLR4 prevents or reverses ethanol-induced neuroimmune responses (Fernandez-Lizarbe et al., 2009; Alfonso-Loeches et al., 2010; Zou 
and Crews, 2014; Bajo et al., 2016). Chronic ethanol exposure may also disrupt the integrity of the blood-brain barrier via TLR4-dependent signaling (Rubio-Araiz et al., 2016). TLR4 was associated with cognitive impairment and anxiety-related behavior during ethanol withdrawal (Pascual et al., 2011; Pascual et al., 2015) and with synaptic remodeling and anxiety induced by binge drinking in adolescent mice (Montesinos et al., 2016). However, our comprehensive study using different species and sexes, different methods to inhibit TLR4, and different tests of chronic, dependence-driven, and binge-like consumption indicates that Tlr4 is not a critical gene for regulating ethanol drinking and inhibition of TLR4 signaling alone would not be an effective therapeutic strategy. Ethanol promotes physical interactions between TLR4 and TLR2 (Fernandez-Lizarbe et al., 2013) and TLR4/TLR2 interactions were implicated in ethanol-induced sedation (Corrigan et al., 2015), which warrants consideration that TLR4 and other neuroimmune mediators may regulate ethanol responses synergistically. Analyses of the conserved cross-species gene networks in alcoholics and animal models exposed to chronic alcohol will help to prioritize immune/inflammatory pathways (and candidate drugs) with improved therapeutic potential for alcohol use disorders.

\section{References}

Alfonso-Loeches S, Pascual-Lucas M, Blanco AM, Sanchez-Vera I, Guerri C (2010) Pivotal role of TLR4 receptors in alcohol-induced neuroinflammation and brain damage. J Neurosci 30:8285-8295. CrossRef Medline

Alfonso-Loeches S, Ureña-Peralta J, Morillo-Bargues MJ, Gómez-Pinedo U, Guerri C (2016) Ethanol-induced TLR4/NLRP3 neuroinflammatory response in microglial cells promotes leukocyte infiltration across the BBB. Neurochem Res 41:193-209. CrossRef Medline

Bajo M, Madamba SG, Roberto M, Blednov YA, Sagi VN, Roberts E, Rice KC, Harris RA, Siggins GR (2014) Innate immune factors modulate ethanol interaction with GABAergic transmission in mouse central amygdala. Brain Behav Immun 40:191-202. CrossRef Medline

Bajo M, Herman MA, Varodayan FP, Oleata CS, Madamba SG, Harris RA, Blednov YA, Roberto M (2015) Role of the IL-1 receptor antagonist in ethanol-induced regulation of GABAergic transmission in the central amygdala. Brain Behav Immun 45:189-197. CrossRef Medline

Bajo M, Montgomery SE, Cates LN, Nadav T, Delucchi AM, Cheng K, Yin H, Crawford EF, Roberts AJ, Roberto M (2016) Evaluation of TLR4 inhibitor, T5342126, in modulation of ethanol-drinking behavior in alcoholdependent mice. Alcohol Alcoholism 51:541-548. CrossRef Medline

Becker HC, Lopez MF (2004) Increased ethanol drinking after repeated chronic ethanol exposure and withdrawal experience in C57BL/6 mice. Alcohol Clin Exp Res 28:1829-1838. CrossRef Medline

Blanco AM, Vallés SL, Pascual M, Guerri C (2005) Involvement of TLR4/ type I IL-1 receptor signaling in the induction of inflammatory mediators and cell death induced by ethanol in cultured astrocytes. J Immunol 175: 6893-6899. CrossRef Medline

Blednov YA, Walker D, Alva H, Creech K, Findlay G, Harris RA (2003) GABAA receptor alpha 1 and beta 2 subunit null mutant mice: behavioral responses to ethanol. J Pharmacol Exp Ther 305:854-863. CrossRef Medline

Blednov YA, Benavidez JM, Geil C, Perra S, Morikawa H, Harris RA (2011) Activation of inflammatory signaling by lipopolysaccharide produces a prolonged increase of voluntary alcohol intake in mice. Brain Behav Immun 25:S92-S105. CrossRef Medline

Blednov YA, Black M, Chernis J, Da Costa A, Mayfield J, Harris RA (2017a) Ethanol consumption in mice lacking CD14, TLR2, TLR4, or MyD88. Alcohol Clin Exp Ther, in press.

Blednov YA, Black M, Chernis J, Da Costa A, Mayfield J, Harris RA (2017b) Sedative and motor incoordination effects of ethanol in mice lacking CD14, TLR2, TLR4, or MyD88. Alcohol Clin Exp Ther, in press.

Blednov YA, Ponomarev I, Geil C, Bergeson S, Koob GF, Harris RA (2012) Neuroimmune regulation of alcohol consumption: behavioral validation of genes obtained from genomic studies. Addict Biol 17:108-120. CrossRef Medline

Corrigan F, Wu Y, Tuke J, Coller JK, Rice KC, Diener KR, Hayball JD, Watkins LR, Somogyi AA, Hutchinson MR (2015) Alcohol-induced seda- tion and synergistic interactions between alcohol and morphine: a key mechanistic role for Toll-like receptors and MyD88-dependent signaling. Brain Behav Immun 45:245-252. CrossRef Medline

Crews FT, Vetreno RP (2016) Mechanisms of neuroimmune gene induction in alcoholism. Psychopharmacology 233:1543-1557. CrossRef Medline

Cross-Mellor SK, Kent WD, Kavaliers M, Ossenkopp KP (2000) Examining the effects of lipopolysaccharide and cholecystokinin on water ingestion: comparing intake and palatability. Brain Res 861:220-232. CrossRef Medline

Cruz MT, Herman MA, Kallupi M, Roberto M (2012) Nociceptin/orphanin FQ blockade of corticotropin-releasing factor-induced gammaaminobutyric acid release in central amygdala is enhanced after chronic ethanol exposure. Biol Psychiatry 71:666-676. CrossRef Medline

Cruz MT, Herman MA, Cote DM, Ryabinin AE, Roberto M (2013) Ghrelin increases GABAergic transmission and interacts with ethanol actions in the rat central nucleus of the amygdala. Neuropsychopharmacology 38 : 364-375. CrossRef Medline

Day HE, Curran EJ, Watson SJ Jr, Akil H (1999) Distinct neurochemical populations in the rat central nucleus of the amygdala and bed nucleus of the stria terminalis: evidence for their selective activation by interleukin1beta. J Comp Neurol 413:113-128. Medline

Dixon C, Sah P, Lynch JW, Keramidas A (2014) GABAA receptor alpha and gamma subunits shape synaptic currents via different mechanisms. J Biol Chem 289:5399-5411. CrossRef Medline

Edwards S, Guerrero M, Ghoneim OM, Roberts E, Koob GF (2012) Evidence that vasopressin $\mathrm{V} 1 \mathrm{~b}$ receptors mediate the transition to excessive drinking in ethanol-dependent rats. Addict Biol 17:76-85. CrossRef Medline

Ferguson C, McKay M, Harris RA, Homanics GE (2013) Toll-like receptor 4 (Tlr4) knockout rats produced by transcriptional activator-like effector nuclease (TALEN)-mediated gene inactivation. Alcohol 47:595-599. CrossRef Medline

Fernandez-Lizarbe S, Pascual M, Guerri C (2009) Critical role of TLR4 response in the activation of microglia induced by ethanol. J Immunol 183:4733-4744. CrossRef Medline

Fernandez-Lizarbe S, Montesinos J, Guerri C (2013) Ethanol induces TLR4/ TLR2 association, triggering an inflammatory response in microglial cells. J Neurochem 126:261-273. CrossRef Medline

Finn DA, Snelling C, Fretwell AM, Tanchuck MA, Underwood L, Cole M, Crabbe JC, Roberts AJ (2007) Increased drinking during withdrawal from intermittent ethanol exposure is blocked by the CRF receptor antagonist D-Phe-CRF(12-41). Alcohol Clin Exp Res 31:939-949. CrossRef Medline

Gilpin NW, Misra K, Koob GF (2008) Neuropeptide Y in the central nucleus of the amygdala suppresses dependence-induced increases in alcohol drinking. Pharmacol Biochem Behav 90:475-480. CrossRef Medline

Gilpin NW, Smith AD, Cole M, Weiss F, Koob GF, Richardson HN (2009) Operant behavior and alcohol levels in blood and brain of alcoholdependent rats. Alcohol Clin Exp Res 33:2113-2123. CrossRef Medline

Gilpin NW, Misra K, Herman MA, Cruz MT, Koob GF, Roberto M (2011) Neuropeptide Y opposes alcohol effects on gamma-aminobutyric acid release in amygdala and blocks the transition to alcohol dependence. Biol Psychiatry 69:1091-1099. CrossRef Medline

Griffin WC 3rd, Lopez MF, Yanke AB, Middaugh LD, Becker HC (2009) Repeated cycles of chronic intermittent ethanol exposure in mice increases voluntary ethanol drinking and ethanol concentrations in the nucleus accumbens. Psychopharmacology 201:569-580. CrossRef Medline

Herman MA, Kallupi M, Luu G, Oleata CS, Heilig M, Koob GF, Ciccocioppo R, Roberto M (2013) Enhanced GABAergic transmission in the central nucleus of the amygdala of genetically selected Marchigian Sardinian rats: alcohol and CRF effects. Neuropharmacology 67:337-348. CrossRef Medline

Hutchinson MR, Zhang Y, Brown K, Coats BD, Shridhar M, Sholar PW, Patel SJ, Crysdale NY, Harrison JA, Maier SF, Rice KC, Watkins LR (2008) Non-stereoselective reversal of neuropathic pain by naloxone and naltrexone: involvement of toll-like receptor 4 (TLR4). Eur J Neurosci 28: 20-29. CrossRef Medline

Jacob TC, Moss SJ, Jurd R (2008) GABA(A) receptor trafficking and its role in the dynamic modulation of neuronal inhibition. Nat Rev Neurosci 9:331-343. CrossRef Medline

June HL, Liu J, Warnock KT, Bell KA, Balan I, Bollino D, Puche A, Aurelian L 
(2015) CRF-amplified neuronal TLR4/MCP-1 signaling regulates alcohol self-administration. Neuropsychopharmacology 40:1549-1559. CrossRef Medline

Kalis C, Kanzler B, Lembo A, Poltorak A, Galanos C, Freudenberg MA (2003) Toll-like receptor 4 expression levels determine the degree of LPSsusceptibility in mice. Eur J Immunol 33:798-805. CrossRef Medline

Lasek AW, Janak PH, He L, Whistler JL, Heberlein U (2007) Downregulation of mu opioid receptor by RNA interference in the ventral tegmental area reduces ethanol consumption in mice. Genes Brain Behav 6:728735. CrossRef Medline

Leclercq S, Cani PD, Neyrinck AM, Stärkel P, Jamar F, Mikolajczak M, Delzenne NM, de Timary P (2012) Role of intestinal permeability and inflammation in the biological and behavioral control of alcohol-dependent subjects. Brain Behav Immun 26:911-918. CrossRef Medline

Leclercq S, Matamoros S, Cani PD, Neyrinck AM, Jamar F, Stärkel P, Windey K, Tremaroli V, Bäckhed F, Verbeke K, de Timary P, Delzenne NM (2014) Intestinal permeability, gut-bacterial dysbiosis, and behavioral markers of alcohol-dependence severity. Proc Natl Acad Sci U S A 111: E4485-E4493. CrossRef Medline

Lippai D, Bala S, Csak T, Kurt-Jones EA, Szabo G (2013) Chronic alcoholinduced microRNA-155 contributes to neuroinflammation in a TLR4dependent manner in mice. PLoS One 8:e70945. CrossRef Medline

Liu J, Lewohl JM, Harris RA, Iyer VR, Dodd PR, Randall PK, Mayfield RD (2006) Patterns of gene expression in the frontal cortex discriminate alcoholic from nonalcoholic individuals. Neuropsychopharmacology 31 : 1574-1582. CrossRef Medline

Liu J, Yang AR, Kelly T, Puche A, Esoga C, June HL Jr, Elnabawi A, Merchenthaler I, Sieghart W, June HL Sr, Aurelian L (2011) Binge alcohol drinking is associated with GABAA alpha2-regulated Toll-like receptor 4 (TLR4) expression in the central amygdala. Proc Natl Acad Sci U S A 108:4465-4470. CrossRef Medline

Mayfield J, Ferguson L, Harris RA (2013) Neuroimmune signaling: a key component of alcohol abuse. Curr Opin Neurobiol 23:513-520. CrossRef Medline

McCarthy DO, Kluger MJ, Vander AJ (1984) The role of fever in appetite suppression after endotoxin administration. Am J Clin Nutr 40:310-316. Medline

Melendez RI (2011) Intermittent (every-other-day) drinking induces rapid escalation of ethanol intake and preference in adolescent and adult C57BL/6J mice. Alcohol Clin Exp Res 35:652-658. CrossRef Medline

Montesinos J, Pascual M, Rodríguez-Arias M, Miñarro J, Guerri C (2016) Involvement of TLR4 in the long-term epigenetic changes, rewarding and anxiety effects induced by intermittent ethanol treatment in adolescence. Brain Behav Immun 53:159-171. CrossRef Medline

O’Dell LE, Roberts AJ, Smith RT, Koob GF (2004) Enhanced alcohol selfadministration after intermittent versus continuous alcohol vapor exposure. Alcohol Clin Exp Res 28:1676-1682. CrossRef Medline

Otis TS, De Koninck Y, Mody I (1994) Lasting potentiation of inhibition is associated with an increased number of gamma-aminobutyric acid type $\mathrm{A}$ receptors activated during miniature inhibitory postsynaptic currents. Proc Natl Acad Sci U S A 91:7698-7702. CrossRef Medline

Pascual M, Baliño P, Alfonso-Loeches S, Aragón CM, Guerri C (2011) Impact of TLR4 on behavioral and cognitive dysfunctions associated with alcohol-induced neuroinflammatory damage. Brain Behav Immun 25: S80-S91. CrossRef Medline

Pascual M, Baliño P, Aragón CM, Guerri C (2015) Cytokines and chemokines as biomarkers of ethanol-induced neuroinflammation and anxietyrelated behavior: role of TLR4 and TLR2. Neuropharmacology 89:352359. CrossRef Medline

Paxinos G, Franklin KBJ (2004) The mouse brain in stereotaxic coordinates. 4th Ed. Elsevier Science (USA).

Qureshi ST, Larivière L, Leveque G, Clermont S, Moore KJ, Gros P, Malo D (1999) Endotoxin-tolerant mice have mutations in Toll-like receptor 4 (Tlr4). J Exp Med 189:615-625. CrossRef Medline

Rhodes JS, Best K, Belknap JK, Finn DA, Crabbe JC (2005) Evaluation of a simple model of ethanol drinking to intoxication in C57BL/6J mice. Physiol Behav 84:53-63. CrossRef Medline

Rhodes JS, Ford MM, Yu CH, Brown LL, Finn DA, Garland T Jr, Crabbe JC (2007) Mouse inbred strain differences in ethanol drinking to intoxication. Genes Brain Behav 6:1-18. Medline
Rimondini R, Sommer W, Heilig M (2003) A temporal threshold for induction of persistent alcohol preference: behavioral evidence in a rat model of intermittent intoxication. J Stud Alcohol 64:445-449. CrossRef Medline

Roberto M, Madamba SG, Moore SD, Tallent MK, Siggins GR (2003) Ethanol increases GABAergic transmission at both pre- and postsynaptic sites in rat central amygdala neurons. Proc Natl Acad Sci U S A 100:20532058. CrossRef Medline

Roberto M, Madamba SG, Stouffer DG, Parsons LH, Siggins GR (2004) Increased GABA release in the central amygdala of ethanol-dependent rats. J Neurosci 24:10159-10166. CrossRef Medline

Roberts AJ, Heyser CJ, Cole M, Griffin P, Koob GF (2000) Excessive ethanol drinking following a history of dependence: animal model of allostasis. Neuropsychopharmacology 22:581-594. CrossRef Medline

Robinson G, Most D, Ferguson LB, Mayfield J, Harris RA, Blednov YA (2014) Neuroimmune pathways in alcohol consumption: evidence from behavioral and genetic studies in rodents and humans. Int Rev Neurobiol 118:13-39. CrossRef Medline

Rubio-Araiz A, Porcu F, Perez-Hernandez M, Garcia-Gutierrez MS, AracilFernandez MA, Gutierrez-Lopez MD, Guerri C, Manzanares J, O'Shea E, Colado MI (2016) Disruption of blood-brain barrier integrity in postmortem alcoholic brain: preclinical evidence of TLR4 involvement from a binge-like drinking model. Addict Biol. In press.

Schmittgen TD, Livak KJ (2008) Analyzing real-time PCR data by the comparative $\mathrm{C}(\mathrm{T})$ method. Nat Protoc 3:1101-1108. CrossRef Medline

Schulteis G, Markou A, Cole M, Koob GF (1995) Decreased brain reward produced by ethanol withdrawal. Proc Natl Acad Sci U S A 92:58805884. CrossRef Medline

Serrats J, Sawchenko PE (2006) CNS activational responses to staphylococcal enterotoxin B: T-lymphocyte-dependent immune challenge effects on stress-related circuitry. J Comp Neurol 495:236-254. CrossRef Medline

Sodhi CP, Neal MD, Siggers R, Sho S, Ma C, Branca MF, Prindle T Jr, Russo AM, Afrazi A, Good M, Brower-Sinning R, Firek B, Morowitz MJ, Ozolek JA, Gittes GK, Billiar TR, Hackam DJ (2012) Intestinal epithelial Tolllike receptor 4 regulates goblet cell development and is required for necrotizing enterocolitis in mice. Gastroenterology 143:708-718.e1-5. CrossRef Medline

Sommer WH, Rimondini R, Marquitz M, Lidström J, Siems WE, Bader M, Heilig M (2007) Plasticity and impact of the central renin-angiotensin system during development of ethanol dependence. J Mol Med 85:1089_ 1097. CrossRef Medline

Szabo G, Lippai D (2014) Converging actions of alcohol on liver and brain immune signaling. Int Rev Neurobiol 118:359-380. CrossRef Medline

Tanda G, Mereu M, Hiranita T, Quarterman JC, Coggiano M, Katz JL (2016) Lack of specific involvement of $(+)$-naloxone and $(+)$-naltrexone on the reinforcing and neurochemical effects of cocaine and opioids. Neuropsychopharmacology 41:2772-2781. CrossRef Medline

Thiele TE, Crabbe JC, Boehm SL 2nd (2014) “Drinking in the Dark" (DID): a simple mouse model of binge-like alcohol intake. Curr Protoc Neurosci 68:9.49.1-9.49.12. CrossRef Medline

Valdez GR, Roberts AJ, Chan K, Davis H, Brennan M, Zorrilla EP, Koob GF (2002) Increased ethanol self-administration and anxiety-like behavior during acute ethanol withdrawal and protracted abstinence: regulation by corticotropin-releasing factor. Alcohol Clin Exp Res 26:1494-1501. CrossRef Medline

Van der Kloot W (1991) The regulation of quantal size. Prog Neurobiol 36:93-130. CrossRef Medline

van Heesch F, Prins J, Konsman JP, Westphal KG, Olivier B, Kraneveld AD, Korte SM (2013) Lipopolysaccharide-induced anhedonia is abolished in male serotonin transporter knockout rats: an intracranial selfstimulation study. Brain Behav Immun 29:98-103. CrossRef Medline

Vendruscolo LF, Roberts AJ (2014) Operant alcohol self-administration in dependent rats: focus on the vapor model. Alcohol 48:277-286. CrossRef Medline

Vezzani A, Maroso M, Balosso S, Sanchez MA, Bartfai T (2011) IL-1 receptor/Toll-like receptor signaling in infection, inflammation, stress and neurodegeneration couples hyperexcitability and seizures. Brain Behav Immun 25:1281-1289. CrossRef Medline

von Meyenburg C, Hrupka BH, Arsenijevic D, Schwartz GJ, Landmann R, Langhans W (2004) Role for CD14, TLR2, and TLR4 in bacterial product-induced anorexia. Am J Physiol Regul Integ Comp Physiol 287: R298-R305. CrossRef Medline 
Wang X, Zhang Y, Peng Y, Hutchinson MR, Rice KC, Yin H, Watkins LR (2016) Pharmacological characterization of the opioid inactive isomers $(+)$-naltrexone and (+)-naloxone as Toll-like receptor 4 antagonists. Br J Pharmacol 173:856-869. CrossRef Medline

Wu X, Fu Y, Knott G, Lu J, Di Cristo G, Huang ZJ (2012a) GABA signaling promotes synapse elimination and axon pruning in developing cortical inhibitory interneurons. J Neurosci 32:331-343. CrossRef Medline

Wu Y, Lousberg EL, Moldenhauer LM, Hayball JD, Coller JK, Rice KC, Watkins LR, Somogyi AA, Hutchinson MR (2012b) Inhibiting the TLR4MyD88 signalling cascade by genetic or pharmacological strategies reduces acute alcohol-induced sedation and motor impairment in mice. Br J Pharmacol 165:1319-1329. CrossRef Medline
Yang JC, Wu SC, Rau CS, Lu TH, Wu YC, Chen YC, Lin MW, Tzeng SL, Wu CJ, Hsieh CH (2014) Inhibition of the phosphoinositide 3-kinase pathway decreases innate resistance to lipopolysaccharide toxicity in TLR4 deficient mice. J Biomed Sci 21:20. CrossRef Medline

Zhao Y, Weiss F, Zorrilla EP (2007) Remission and resurgence of anxiety-like behavior across protracted withdrawal stages in ethanol-dependent rats. Alcohol Clin Exp Res 31:1505-1515. CrossRef Medline

Zou JY, Crews FT (2014) Release of neuronal HMGB1 by ethanol through decreased HDAC activity activates brain neuroimmune signaling. PloS One 9:e87915. CrossRef Medline 